\title{
TU/e EmonONEN

\section{A green intermodal service network design problem with travel time uncertainty}

\section{Citation for published version (APA):}

Demir, E., Burgholzer, W., Hrusovsky, M., Arikan, E., Jammernegg, W., \& Van Woensel, T. (2016). A green intermodal service network design problem with travel time uncertainty. Transportation Research. Part B: Methodological, 93B, 789-807. https://doi.org/10.1016/j.trb.2015.09.007

\section{Document license:}

TAVERNE

DOI:

10.1016/j.trb.2015.09.007

Document status and date:

Published: 01/01/2016

\section{Document Version:}

Publisher's PDF, also known as Version of Record (includes final page, issue and volume numbers)

\section{Please check the document version of this publication:}

- A submitted manuscript is the version of the article upon submission and before peer-review. There can be important differences between the submitted version and the official published version of record. People interested in the research are advised to contact the author for the final version of the publication, or visit the $\mathrm{DOI}$ to the publisher's website.

- The final author version and the galley proof are versions of the publication after peer review.

- The final published version features the final layout of the paper including the volume, issue and page numbers.

Link to publication

\section{General rights}

Copyright and moral rights for the publications made accessible in the public portal are retained by the authors and/or other copyright owners and it is a condition of accessing publications that users recognise and abide by the legal requirements associated with these rights.

- Users may download and print one copy of any publication from the public portal for the purpose of private study or research.

- You may not further distribute the material or use it for any profit-making activity or commercial gain

- You may freely distribute the URL identifying the publication in the public portal.

If the publication is distributed under the terms of Article 25fa of the Dutch Copyright Act, indicated by the "Taverne" license above, please follow below link for the End User Agreement:

www.tue.nl/taverne

Take down policy

If you believe that this document breaches copyright please contact us at:

openaccess@tue.nl

providing details and we will investigate your claim. 


\title{
A green intermodal service network design problem with travel time uncertainty
}

\author{
Emrah Demir ${ }^{\mathrm{a}}$, Wolfgang Burgholzer ${ }^{\mathrm{b}}$, Martin Hrušovský ${ }^{\mathrm{b}, *}$, Emel Arıkan $^{\mathrm{b}}$, \\ Werner Jammernegg ${ }^{\mathrm{b}}$, Tom Van Woensel ${ }^{\mathrm{a}}$ \\ a School of Industrial Engineering, Operations, Planning, Accounting and Control (OPAC), Eindhoven University of Technology, \\ Eindhoven, $5600 \mathrm{MB}$, The Netherlands \\ ${ }^{\mathrm{b}}$ Institute for Production Management, WU Vienna University of Economics and Business, Vienna, Welthandelsplatz 1 , \\ Vienna 1020, Austria
}

\section{A R T I C L E I N F O}

\section{Article history:}

Available online 3 November 2015

\section{Keywords:}

Stochastic service network design problem

Intermodal transportation

$\mathrm{CO}_{2}$-equivalent emissions

Travel time uncertainty

Demand uncertainty

Sample average approximation method

\begin{abstract}
A B S T R A C T
In a more and more competitive and global world, freight transports have to overcome increasingly long distances while at the same time becoming more reliable. In addition, a raising awareness of the need for environmentally friendly solutions increases the importance of transportation modes other than road. Intermodal transportation, in that regard, allows for the combination of different modes in order to exploit their individual advantages. Intermodal transportation networks offer flexible, robust and environmentally friendly alternatives to transport high volumes of goods over long distances. In order to reflect these advantages, it is the challenge to develop models which both represent multiple modes and their characteristics (e.g., fixed-time schedules and routes) as well as the transhipment between these transportation modes. In this paper, we introduce a Green Intermodal Service Network Design Problem with Travel Time Uncertainty (GISND-TTU) for combined offline intermodal routing decisions of multiple commodities. The proposed stochastic approach allows for the generation of robust transportation plans according to different objectives (i.e., cost, time and greenhouse gas (GHG) emissions) by considering uncertainties in travel times as well as demands with the help of the sample average approximation method. The proposed methodology is applied to a real-world network, which shows the advantages of stochasticity in achieving robust transportation plans.
\end{abstract}

(c) 2015 Elsevier Ltd. All rights reserved.

\section{Introduction}

Freight transportation activities are closely related to the movement of goods between different locations within a supply chain network. Global outsourcing activities of companies aim to use advantages and expertise of suppliers from all over the world (Kotabe and Murray, 2004). The growing specialization and internalization of the world trade has led to increasing distances between suppliers, producers and final customers. This development resulted in the increasing volumes of global transportation operations during the last decade (see, e.g., OECD, 2010; UNCTAD, 2013).

\footnotetext{
* Corresponding author. Tel.: +43131336 5632 .

E-mail addresses: e.demir@tue.nl (E. Demir), wolfgang.burgholzer@wu.ac.at (W. Burgholzer), martin.hrusovsky@wu.ac.at (M. Hrušovský), emel.arikan@wu.ac.at (E. Arıkan), werner.jammernegg@wu.ac.at (W. Jammernegg), t.v.woensel@tue.nl (T.V.Woensel).
} 
The growth in international shipping also influences the volume of inland transportation operations. Within the EU-28 (European Union's 28 countries), about 2,100 billion ton-kilometers of goods were transported in 2012, with road transportation accounting for about three quarters (75.5\%) of this volume (Eurostat, 2013). The high share of road transportation can be explained by a relatively dense transportation network enabling fast door-to-door transports and high flexibility in route planning (Kummer, 2006). However, the growing volumes of road transportation contribute to congestion on road, which leads to delay, disruption, and other negative impacts on the reliability of transportation (European Commission, 2012). Moreover, transportation is one of the main attributes to the growth of carbon dioxide equivalent $\left(\mathrm{CO}_{2} \mathrm{e}\right)$ emissions (European Commission, 2014), where the impact of road transportation is significant. Therefore, companies are searching for alternative transportation options that allow them to minimize the negative impacts of road transportation and improve the economic and environmental performance of their distribution systems (see, e.g., Forkenbrock, 1999; Demir et al., 2015).

Freight transportation services involve various transportation modes - road, rail, maritime, air and pipeline. The number of transportation alternatives can be increased by using different transportation modes and combining them in multimodal transportation chains. Multimodal transportation not only promotes advantages of each transportation mode but also releases their disadvantages. Multimodal transportation is mainly used on routes with high volumes and long distances where the economies of scale and environmental advantages offered by rail or maritime outweigh the additional costs and possible mode-connection delays (Vannieuwenhuyse et al., 2003). The handling activities during transhipment can be facilitated by using a standardized loading unit (i.e., container) which is normally required in intermodal transportation (ECMT, 1993).

As defined by the ECMT (1993) intermodal freight transportation is a specialization of multimodal transportation. It consecutively uses multiple modes while moving the goods within a loading unit. Thus, the goods themselves do not have to be handled, but only the loading unit. Since a loading unit is often a standardized container, intermodal transportation is also referred to as containerized transportation.

Intermodal transportation has numerous advantages in addition to the noted flexibility offered by multimodal transportation. Standard sizes, faster transhipments, and reduced packaging expenses are essential benefits for shippers with large volumes (Jennings and Holcomb, 1996). Intermodal transportation offers a fast alternative to unimodal transportation by road especially for long distances and, therefore, its volume has been growing significantly over the last decade. Thereby, an effective intermodal transportation is necessary for bringing maritime containers arriving to European ports to hinterland customers. In particular, rail and maritime play an important role in sustainable transportation (UIC, 2012). The complexity of transportation plans lies in the use of multiple transportation modes and uncertainty in travel times and demands. In addition, constraints (e.g., fixed time schedules and routes, transhipment, sequence of transportation services, etc.) need to be considered in the planning phase.

In response to the above-mentioned complexities, this paper presents a stochastic mixed integer linear programming formulation based approach for an advanced intermodal transportation planning problem on a transportation network including different transportation modes and transhipment locations. The aim of the paper is to generate optimal and robust transportation plans using the intermodal transportation network. Capacity, travel and service times as well as costs and greenhouse gases (GHGs) of each specific service are taken into account. Moreover, the proposed methodology allows planners to optimize their transportation plans according to weightable objectives (i.e., cost, time and GHG emissions) and considers uncertainties connected with travel times as well as demands.

The paper is structured as follows. Section 2 describes the problem definition and gives an overview of the literature. Section 3 then outlines some of the modeling methodologies used for incorporating uncertainties as well as environmental criteria into the solution methodology while Section 4 describes the mathematical formulation. Section 5 focuses on the application of the proposed methodology to a sample case study based on real-world intermodal transportation network combining road, rail and inland waterway. Section 6 discusses the computational results when applying the stochastic approach to bigger real-life instances. Conclusions and future research directions are stated in Section 7.

\section{Problem description}

In intermodal transportation, containers can be transported by different transportation modes operated between terminals. While most of the transports on the road are not scheduled, transportation services (rail, air and maritime) in intermodal transportation networks normally follow fixed schedules. In that case, Service Network Design (SND) provides intriguing possibilities for the reproduction of transportation flows on more than one mode including schedules. Moreover, it offers methodological possibilities which enable the representation of transhipments as well as the consolidation of containers.

The problem addressed in this paper is routing and scheduling of customers' transportation orders by selecting available as well as also planning transportation services within an intermodal transportation network. A service can be characterized by its origin, destination, intermediate terminals, transportation mode, route, service capacity and starting time window (SteadieSeifi et al., 2014). While research on the design of services within networks is quite extensive, SND literature concerned with the selection of available services for specific shipments is scarce and less advanced (see, e.g., Crainic, 2000; 2003; Wieberneit, 2008). The orders are characterized by a certain number of containers which have to be transhipped from origin to destination within specified time windows. Whereas the transportation cannot start before a specified release time, late arrivals to destinations are allowed with a penalty cost.

Since some of the services depart according to fixed schedules, it is not possible to wait for late containers due to unexpected delays during transportation. Fig. 1 displays a transportation network which shows one possible intermodal route for an order with origin $A$ and destination $D$. The pickup time thereby is $T_{d e p}$ while the due date at the destination is $T_{d u e}$. The presented route 


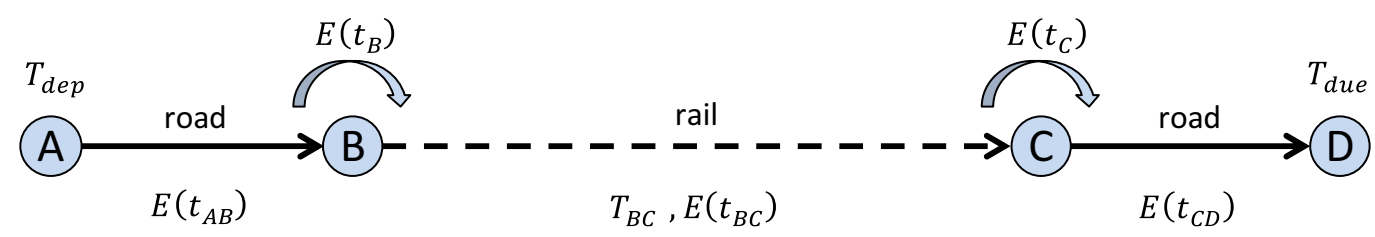

Fig. 1. A sample intermodal transportation route.

takes the transported containers by truck from location $A$ to location $B$ where a transhipment to train takes place (with estimated duration $E\left(t_{B}\right)$ ). This train transports the containers from $B$ to $C$, where they are transhipped back to truck for final delivery to destination $D$.

Assuming these connections are available at any time which is common in most Vehicle Routing Problems (VRPs), selected paths are considered under the condition that a delivery reaches destination $D$ before its due date.

$$
T_{d e p}+E\left(t_{A B}\right)+E\left(t_{B}\right)+E\left(t_{B C}\right)+E\left(t_{C}\right)+E\left(t_{C D}\right) \leq T_{d u e} .
$$

To represent a scenario with a combination of fixed and yet to be generated schedules, in this example rail transportation between $B$ and $C$ has a fixed departure time of $T_{B C}$ while truck transportation between $C$ and $D$ has a wide starting time window allowing the generation of a schedule with starting time $T_{C D}$. In other words, transportation units must arrive at $B$ in time in order to reach service $B C$ whereas service $C D$ is generated based on the arrival time at $C$. If routing decisions are only based on estimated travel times, the following constraints for path feasibility occur.

$$
\begin{aligned}
& T_{d e p}+E\left(t_{A B}\right)+E\left(t_{B}\right) \leq T_{B C}, \\
& T_{B C}+E\left(t_{B C}\right)+E\left(t_{C}\right)+E\left(t_{C D}\right) \leq T_{\text {due }} .
\end{aligned}
$$

However, estimated travel times do not reflect the uncertainties of the real world. Uncertainties of travel times (e.g., due to high traffic density, external events) create difficulties in routing plans especially for fixed schedules. For example, a delay between $A$ and $B$ could affect the ability to reach the scheduled rail service, leading to an infeasible situation. To present such a situation, a three-point distribution is considered with one possible realization below $(E(t) x$ with $0<x<1)$, one above $(E(t)(2-$ $x)$ ) and one directly at the expected travel time $E(t)$ for both road services. If the realizations above the expected value lead to late arrivals compared to $T_{B C}$ and $T_{d u e}$, respectively, the probability of route infeasibility despite feasibility with expected travel times would be

$$
P\left[t_{A B}=E\left(t_{A B}\right)(2-x)\right]+P\left[t_{C D}=E\left(t_{C D}\right)(2-x) \mid t_{A B} \neq E\left(t_{A B}\right)(2-x)\right] .
$$

Thus, vehicle routing plans should be reliable and accurate in response to uncertainties. In addition, there is an increasing need for dependable on-time deliveries considering tied-up capital, such as inventories (Danese et al., 2012). As a result, the reliability of model outputs is more and more considered as a key deliverable of an optimization model. A direct consequence of this changed operating environment is raising interest in optimization techniques that account for time-dependent variables, such as travel times, in a network (Chang et al., 2009; Guener et al., 2012).

Owing to tremendous achievements in both fields of operations research and computer science, optimization models have been adapted as such, that uncertainties can be taken into account. The main purpose is to account for variabilities beforehand in order to develop transportation plans which are more accurate and robust to external influences. Improved collection of realtime traffic flow information over the last decade, which enables the identification of traffic flow distributions, builds the data basis for such approaches. On an operational level within the transportation sector, the VRP and its multitude of extensions play a pivotal role in this context (see, e.g., Bertsimas and Simchi-Levi, 1996; Gendreau et al., 1996; Eksioglu et al., 2009; Agra et al., 2013).

In order to include uncertainties into SND formulations, SND methodologies can be divided into static and dynamic problems. While all the characteristics of (possible) services are fixed in static problems, dynamic problems allow modifications of decision variables. Since research on dynamic SND problems is still in its early stages, there is a lack of applications as well as new methods for service network environments. Whilst rare cases have addressed demand uncertainty, to the best of our knowledge, there is little attention to travel time uncertainties (e.g., Crainic et al., 2011; Bai et al., 2014). However, practitioners suggest that travel time uncertainty is as important as demand uncertainty for accurate routing plans.

In response, a capacitated multi-commodity Green Service Network Design formulation which takes uncertainties in travel times (in addition to demand) into account is proposed in this paper. In order to exploit the distinct advantages of SND, we consider an intermodal environment, in which the network consisting of transhipment locations as well as services operating between them with their frequency, itinerary and schedule is provided. The point of interest is not only on the design of scheduled services but also on the optimal selection of available services in order to serve a set of orders. This sequence of services, then, is the routing plan. We consider travel time uncertainties by using the Sample Average Approximation (SAA) method which results in the routing plan that is reliable and robust to external variabilities (see Section 4.2). The optimal routing plan is chosen according to different objectives (e.g., transportation costs, time, GHG emissions) which could be prioritized. Moreover, we consider a continuous time with a certain planning horizon within which orders can be assigned to services. 
Thus, the scientific contribution of this study is three-fold: (i) to provide a stochastic linear mixed integer programming formulation for the green intermodal SND problem with uncertain travel times (GISND-TTU), (ii) to implement the well-known SAA method to solve GISND-TTU, (iii) to demonstrate the methodology with a real-life case study.

\section{Modeling methodology}

In order to solve the mathematical formulation presented in Section 4, some of the input data (e.g., services, travel times) needs to be prepared in advance. Therefore the interpretation of the underlying network and its schedules is described in Section 3.1. The approach considers environmental criteria next to time- and monetary-dependent factors as discussed in Section 3.2. Section 3.3 describes the problem faced when including uncertain travel times in the SND environment.

\subsection{Modeling the transportation network}

The network is modeled by means of nodes and arcs. The nodes are intermodal transportation terminals while the arcs represent the scheduled services. In contrast to traditional graphs describing transportation networks, the network consists of multiple arcs (or services) between two nodes in order to represent the problem described above (e.g. Andersen et al., 2009). In addition, more than one possible connection between two specific nodes and the handling of loading units at terminals are reflected in the formulation.

The term service is defined as a transportation with a specific vehicle. A service, thereby, is specified by its scheduled start time window as well as travel time (or service time) and route. While the start time windows are constant, travel times can take on values of varying degrees, depending on the traffic state and infrastructure utilization. As there can be multiple scheduled transports between terminals, the network has to represent multiple schedules between these transhipment points. As already mentioned before, the focus is not exclusively on the tactical scheduling of services, but also on their operational sequencing to routing plans which fulfil the demand and provide robust solutions with respect to the uncertainties considered. Thereby, starting time windows for services with fixed schedules can be rather small while larger time windows for other services enable the path-dependent design of their actual start times and thus schedule. That way the contrast between differing modes in regard to the proportion of services with fixed schedules can be represented. In addition to the scheduled start time as well as the service time itself, each service is characterized by its free capacity in terms of loading units (e.g., containers) as well as its (approximated) costs and generation of GHG emissions (see Section 3.2) when using one of these open container slots. The services, thereby, have varying specifications which makes our problem one with inhomogeneous fleet.

Successive services are linked at terminals. Thereby, if two successive services are executed by different vehicles, transhipments have to take place. However, since two successive services could be operated by the same vehicle there is not always the need for transhipment. Transhipment locations, like services, are characterized by the time, costs and emissions per container transhipped. Thereby, the model enables the representation of terminal utilization and its impact on transhipment time. The orders to be fulfilled are specified by the amount of containers demanded, origin and destination node, the earliest departure and the latest arrival time of the delivery as well as penalty costs accounting for delayed delivery.

For each type of service, a brief overview of the transportation mode is provided and followed, in Section 3.2, by the modeling of its environmental impacts. Although the model is also suitable for air freight and sea shipping, the transportation modes covered in this paper are based on the case study (see Section 5) and thus include road, rail and inland waterway transportation.

- Road transportation: Road enables reliable and speedy freight transportation, where goods can be supplied to warehouses and retailers in a timely fashion. In the last decade, a shift towards road transportation has been recorded in European Union (EU). In 2011, road transportation made up over half of freight movements in most of the member states of EU (EU, 2013). Approximately 14,933 million tonnes of freight were transported by road in the EU-28 (EU's 28 states). A comparison between road and other modes of transportation shows that, in 2010, the quantities of freight transported by road in the EU-28 equaled approximately nine times of the amount transported by the other modes of transportation.

- Rail transportation: A freight train is a combination of freight wagons hauled by one or more locomotives on a railway, transporting cargo between the origin and the destination as part of the transportation chain. A freight train can be categorized into electric or diesel locomotives: the former is powered by electricity from overhead lines; and the latter is a type of railway locomotive in which the prime mover is a diesel engine. Different locomotives could result in significantly different external costs. Rail is a more efficient transportation mode than road in terms of ton-kilometers hauled per unit of energy consumed. However, a shipment by rail is not as flexible as road transportation, which results in a great proportion of freight being hauled by trucks in the world. In 2010, EU-28's freight transportation by rail amounted to 1,589 million tons (EU, 2013).

- Inland waterway transportation: The inland waterway transportation denotes the transportation of goods over any distance by barge through canals, rivers, large deep lakes, lochs, and estuaries. It provides a great opportunity for the transportation of freight in Europe. Approximately more than 37,000 kilometres of waterways connect hundreds of cities and industrial regions (EU, 2013). Although the transportation capacity might be sometimes limited by low water levels, inland waterway transportation is known for its reliability, low transportation costs and low environmental impact (via donau, 2007). 


\subsection{Modeling the environmental criteria}

GHGs are the most studied externality of freight transportation. They cause atmospheric changes and climate disruptions which are harmful to the natural and built environments, and pose health risks. GHGs are not classified as a pollutant in the classical sense. However, the United States Environmental Protection Agency (EPA) recognized that GHGs pose a danger to human health and welfare in 2009. GHGs absorb and emit radiations within the thermal infra-red range in the atmosphere, and significantly raise the Earth's temperature. The primary transportation-related man-made greenhouse gases in the Earth's atmosphere are carbon dioxide $\left(\mathrm{CO}_{2}\right)$, methane $\left(\mathrm{CH}_{4}\right)$, nitrous oxide $\left(\mathrm{N}_{2} \mathrm{O}\right)$ and ozone $\left(\mathrm{O}_{3}\right) \cdot$ As $\mathrm{CO}_{2}$ is the dominant man-made $\mathrm{GHG}$, the impacts of other gases can also be calculated based on carbon dioxide equivalent $\left(\mathrm{CO}_{2} \mathrm{e}\right)$. There are numerous studies showing that it is very likely that GHGs are a major contributor to the climate change that the world is facing nowadays. The impact of emissions on climate change is assessed by a comparison between the actual temperature changes in the last 100 years and those that are provided in the models with or without human influence. It is found that the actual temperature changes are very similar to those provided by the model in which the human influence is taken into account (IPCC, 2007). In particular, the Intergovernmental Panel on Climate Change has estimated that 13.1\% of the GHGs emissions is caused by the transportation sector. As of June 2015, the level of GHGs is estimated to be equal to 402.80 parts per million (ppm), and is still increasing (ESRL, 2015).

The amount of emissions caused by transportation is dependent on the energy needed for moving the vehicle which can be expressed as its fuel consumption. There exist a number of models for calculating fuel consumption as shown by Demir et al. (2011) and Demir et al. (2014). These models consider a number of factors which can be divided into three categories. Firstly, fuel consumption is dependent on the vehicle characteristics represented by the mass of the vehicle, air and rolling resistance, engine and transmission efficiency, engine speed and energy needed for auxiliaries (Barth and Boriboonsomsin, 2008; Bowyer et al., 1985). In addition, route and driving characteristics, such as gradient, number of accelerations and decelerations, speed of the vehicle and driving behaviour need to be considered (Ahn et al., 2002; Eichlseder et al., 2009). Last but not least, the load factor of the vehicle influences the amount of fuel needed for transporting goods on a certain road.

However, the use of these models requires detailed input data which is in many cases not available. Therefore a number of models and calculators based on real-world measurements and recommended values for the important factors have been developed (e.g., Boulter and McCrae, 2007; Eichlseder et al., 2009; IFEU, 2011). These models can be used for calculating emissions using predefined data for a representative vehicle as well as for cases when the input data for a concrete vehicle is known. The methodologies used in this paper for calculating emissions for each transportation mode and for transhipment activities in terminals are shortly described in the next subsections.

\subsubsection{Road freight transportation}

In case of road transportation, the Passenger car and Heavy duty vehicle Emission Model (PHEM) developed by TU Graz is an important basis for the Handbook on Emission Factors for Road Traffic (HBEFA) that offers fuel consumption factors for vehicles with different engine types driving on different road categories (Eichlseder et al., 2009). These factors are based on real-world measurements simulating predefined driving cycles and give the fuel consumption for an empty as well as fully loaded vehicle. A linear relationship between the load factor and the fuel consumption of the vehicle is assumed to simplify the modeling approach and therefore the fuel consumption can easily be calculated for different loads as in Bauer et al. (2010). In addition to the road category and load factor, the gradient also plays an important role. According to IFEU (2011), the influence of gradients on fuel consumption in road transportation is $5 \%$ for hilly and $10 \%$ for mountainous countries.

PHEM interpolates the fuel consumption from the engine maps according to the course of engine power demand and engine speed in the driving cycles. The actual engine power $(P)$ can be calculated as $P=P_{r r}+P_{a r}+P_{a c c}+P_{g r}+P_{a u}+P_{t l}$, where $P_{r r}=$ $M g\left(f r_{0}+f r_{1} v+f r_{2} v^{2}+f r_{3} v^{3}+f r_{4} v^{4}\right) v$ is the rolling resistance, $P_{a r}=0.5 C_{d} A \rho v^{3}$ is the air resistance, and $P_{a c c}=\left(M+m_{r o t}\right) a v$ is the acceleration. Moreover, $P_{g r}=M g \omega 0.01 v$ is the gradient resistance, $P_{a u}=P_{0} P_{\text {rated }}$ is the power demand for auxiliaries and $P_{t l}=P_{d r} / \eta_{t}-P_{d r}$ is the transmission losses, where $f r_{0}$ to $f r_{4}$ are the rolling resistance coefficients, $m_{\text {rot }}$ is the reduced mass for rational accelerated part, $P_{0}$ is the power demand of the auxiliaries as ratio to the rated power $P_{\text {rated }}$, and $P_{d r}$ is the power to overcome the driving resistances. The total emission value can be calculated under the transient conditions

$$
E_{\text {trans }}(t)=E_{q s}+P_{\text {rated }}+F_{\text {trans }},
$$

where $E_{q s}$ is the quasi-steady-state emission value interpolated from steady-state emission map (in gram/hour), $P_{\text {rated }}$ is the rated engine power (kilowatt) (since emission values are normalized to the rated power), $F_{\text {trans }}(t)$ is the dynamic correction function ((gram/hour)/kilowatt rated power). More information can be found in Boulter and McCrae (2009).

\subsubsection{Rail freight transportation}

The emissions of rail transportation are also dependent on a number of factors, such as rolling and aerodynamic resistance, speed and acceleration profiles as well as gradient (Boulter and McCrae, 2007). However, as the comparison with real-world values shows, energy consumption of a train can be related to its gross weight in tons as shown in the following formula (IFEU, 2011)

$$
E C=1200 * G W T^{-0.62},
$$

where EC is the energy consumption of the train in kilowatt hours and GWT is its gross weight in tons. The values calculated in this formula are valid especially for trains between 600 and 1800 tons gross weight which is a range typical also for 
container trains. The results are valid for hilly countries and have to be multiplied by 0.9 for flat and by 1.1 for mountainous countries (IFEU, 2011). In order to calculate the amount of emissions from the energy consumption, the result has to be multiplied by the specific emission factor. Here it has to be differentiated between the diesel train causing emissions by burning diesel and the electric train where the emissions are only caused by energy production and not by energy consumption (Kranke et al., 2011).

\subsubsection{Inland waterway freight transportation}

In case of inland waterway transportation (IWT) the available calculators usually use a fixed average emission factor per ton kilometre (see, e.g., IFEU, 2011; 2012) or use the same methodology for IWT and sea transportation (NTM, 2008) ignoring specific factors influencing the fuel consumption of IWT. As a consequence, the results are inaccurate and do not show the real performance of IWT. Therefore we apply the ARTEMIS model developed by Boulter and McCrae (2007) which allows a more realistic emission calculation based on detailed input data.

The estimation of emissions by ARTEMIS is based on the vessel characteristics (type, length, breadth, draught, number of propellers), route properties (waterway depth and width, distance, vessel speed and direction) and cargo characteristics (type and weight). Based on these parameters, the model calculates resistances needed for the determination of engine power and energy consumption which gives information about the amount of emissions released into the air. The energy consumption (EC) in kilojoule/ton kilometre is calculated as

$$
E C=\frac{P_{d} * S F C * F C V}{10^{3} * V * R L},
$$

where $P_{d}$ represents the power demand of the engine to overcome driving resistances in kilowatt, SFC is the specific fuel consumption in gram/kilowatt hour, FCV determines the fuel calorific value in kilojoule/kilogram, $V$ is the speed of the vessel in kilometres/hour and $R L$ is the reference load in tons (Boulter and McCrae, 2007). In order to calculate emissions, EC has to be multiplied by the specific emission factor.

\subsubsection{Emissions from transhipment}

In intermodal transportation the transhipment operations in terminal (or port) also contribute to the overall $\mathrm{CO}_{2} e$ emissions needed in a specific transportation chain. The amount of emissions released in a certain terminal depends on the infrastructure and the handling equipment used for the movement of containers. As Geerlings and van Duin (2011) show in the example of the port of Rotterdam, on its way from the sea ship to the hinterland transportation mode the container has to go through various operations in the terminal within which it is transported by different vehicles like cranes, reach stackers or automated guided vehicles. The total energy in form of electricity or diesel needed for the movement of these vehicles was estimated to 18.25 kilowatt hours/transhipment from sea ship to rail which is also the value used in this paper for sea ports. In case of smaller inland terminals the factor of 4.4 kilowatt hours/transfer of one container is applied as recommended by IFEU (2011).

\subsubsection{Emission factors and general assumptions}

Since the energy consumption does not produce any emissions at all in case of electric trains, the well-to-wheel (WTW) emission scope was chosen in order to make emissions from different transportation modes comparable. This scope includes emissions from energy consumption and energy production (Kranke et al., 2011). The emission factor used for diesel therefore is 3.24 kilogram $\mathrm{CO}_{2} e$ emissions per ton of diesel while for electric energy specific emission factors are taken for each country as proposed by IFEU (2011) and DSLV (2013). In order to express the emissions in terms of costs for the objective function of the planning model, a value of $€ 70 /$ ton of $\mathrm{CO}_{2} e$ emissions was chosen as recommended by the German Federal Environment Agency (PLANCO, 2007).

The amount of emissions released per TEU strongly depends on the capacity utilization of the vehicle. Whereas the relationship between the load factor and the amount of emissions is linear for trucks, the emission functions for trains and inland vessels have an exponential character. Hence, in order to reduce the complexity, the emissions per TEU were calculated assuming a utilization of $80 \%$ for trains (PLANCO, 2007) and 90\% for inland vessels (via donau, 2006).

\subsection{Modeling the uncertainty}

Important aspects of stochastic network models are the formulation of the recourse and the solution method. In the transportation planning context, stochasticity is in many studies included by considering demand uncertainty. For example, Jaillet (1988) and Laporte et al. (1994) study a stochastic traveling salesman problem (TSP) under uncertain demand with a so-called simple recourse where no second-stage optimization is performed. The authors find an optimal a priori tour to minimize expected cost and the recourse includes "simply" skipping the zero demand nodes after the uncertainty is resolved. It is important to note that the a priori tour remains feasible under any demand realization.

Few studies that consider stochasticity in network design are Lium et al. (2009), Hoff et al. (2010), and Bai et al. (2014). Lium et al. (2009) study a two-stage stochastic model where the first-stage decision is the design of the network under demand uncertainty and the second stage is about determining the commodity flows after demand realization. Their focus is on the design problem while our focus lies on planning the commodity flow when there is still uncertainty about demand. Hoff et al. (2010) 
study the network design and commodity flow in a single stage model with demand uncertainty. Excess demand is handled by a high-cost ad-hoc capacity. We assume a similar recourse: if demand is higher than planned the excess demand is assigned to a scheduled service if there is free capacity or to a truck which is assumed to be always available. Handling of excess demand is penalized with a higher service charge. Bai et al. (2014) extends the work by Lium et al. (2009) by considering the possibility of vehicle rerouting at the second stage. Similar to Lium et al. (2009), we define robustness with respect to demand uncertainty as the ability of a plan to deal with varying demand in a cost effective manner.

While inclusion of demand uncertainty is rather straightforward, travel time uncertainty requires a more detailed treatment. Uncertain travel times, for example, are considered in the shortest path problem by Verweij et al. (2003) and in the VRPs by Kenyon and Morton (2003). The authors do not make any recourse decision but the recourse function is assumed to be the lateness or a penalty for the lateness. Again, the a priori path/route is followed and remains feasible under any travel time realization. In our case with scheduled services, "simple" recourse is not easy to define. If we want that the route remains feasible under any realization we have to consider the worst case realizations for all the random variables which makes the solution extremely conservative. Therefore we include a probabilistic constraint to control the reliability of the plan. If a scheduled service cannot be reached because of delays in the previous services, then replanning is required to take an emergency action in real time. In order to avoid such situations we enforce a minimum level of reliability, i.e., the probability of missing a service and hence replanning should be lower than a predefined level. We focus on the possible delays and do not consider shorter than scheduled travel times. A similar approach is taken by Agra et al. (2013) for the VRP.

\section{The green intermodal service network design problem}

In this section we depict our modeling approach for the selection of robust routing plans. The foundation is a deterministic linear mixed-integer programming formulation, which is used for the selection and sequencing of services in order to form routing plans. The robustness of these plans, then, results from the inclusion of uncertainties by the SAA method. Section 4.1 focuses on the central advancement done by this research. The solution methodology and an extension to the model in order to reflect travel time uncertainties and also demand uncertainties are presented in the sequential Sections 4.2 and 4.3 .

\subsection{Mathematical formulation}

A network consisting of services $s \in \mathcal{S}$ (scheduled transports) and nodes $i, j \in \mathcal{N}$ (transhipment locations) forms the basis for the routing decisions. Each service, since it is connected to a schedule and vehicle, is unique and connects transhipment locations $i$ and $j$. Therefore, $\delta^{s}\left(i, j, v, D_{m}^{s}\right)=\{(s \in \mathcal{S}) \mid i \in \mathcal{N}$ and $j \in \mathcal{N}$ and $v \in \mathcal{V}\}$ is a set of services executed by vehicle $v$ between origin $i$ and destination node $j$ within the starting time window bounded by $T_{\min }^{s}$ and $T_{\max }^{s}$. In addition to $s$, variables $q$ and $r$ are also used to represent services. In order to improve the computability of the mathematical model, the scope of the network is reduced beforehand to only reflect viable service options. The considered transhipment locations result from these pre-selected services. The services are characterized by their scheduled departure time $D_{m}^{s}$ and service time $t_{m}^{s}$ as well as service slot price $c^{s}$ and $\mathrm{CO}_{2} \mathrm{e}$ emissions per container $e^{s}$. Service time uncertainties are reflected by multiple runs of the deterministic optimization model with different samples taken from their distribution function $(m \in \mathcal{M})$. We assume that the service time for a service is a random variable which takes values in set $\Phi_{i j}^{s} . t_{m}^{s}$ is the $m^{\text {th }}$ element of set $\Phi^{s}$ with the corresponding probability $\pi_{m}^{s}$ (see Section 4.2). Services on the road as well as transhipments are - due to their lack of scheduled supply in reality - assumed to be available when needed. Their respective service times are dependent on data reflecting the traffic flow and infrastructure utilization.

Transport orders $p \in \mathcal{P}$ are represented by their demand at the origin $i$ and destination $j$ nodes $d^{p}$ as well as earliest release $\Gamma_{\text {release }}^{p}$ and due time $\Gamma_{\text {duetime }}^{p}$. Based on that, $\gamma^{p}(i, j)=\{(p \in \mathcal{P}) \mid i \in \mathcal{N}$ and $j \in \mathcal{N}\}$ is a set of orders with origin $i$ and destination node $j$. While the release time represents a hard time constraint to work with, the due time is represented as soft constraint, leading to penalty cost for late deliveries. The decision variables include continuous variables for containers serviced $\left(x^{s p}, z^{q r p}\right.$, $\left.n_{j}\right)$ as well as binary variables for the services in use in the resulting routing plans $\left(y^{s p}, y^{s}\right)$.

\begin{tabular}{ll} 
Sets: & \\
$\mathcal{P}$ & Set of transportation orders \\
$\mathcal{S}$ & Set of transportation services \\
$\mathcal{V}$ & Set of vehicles \\
$\mathcal{N}^{+}$ & Set of start terminals of transportation orders \\
$\mathcal{N}^{-}$ & Set of end terminals of transportation orders \\
$\mathcal{N}$ & Set of all transhipment locations \\
$\mathcal{M}$ & Set of scenarios with different traveling time values \\
$\mathcal{K}$ & Set of scenarios with different demand values \\
\hline
\end{tabular}




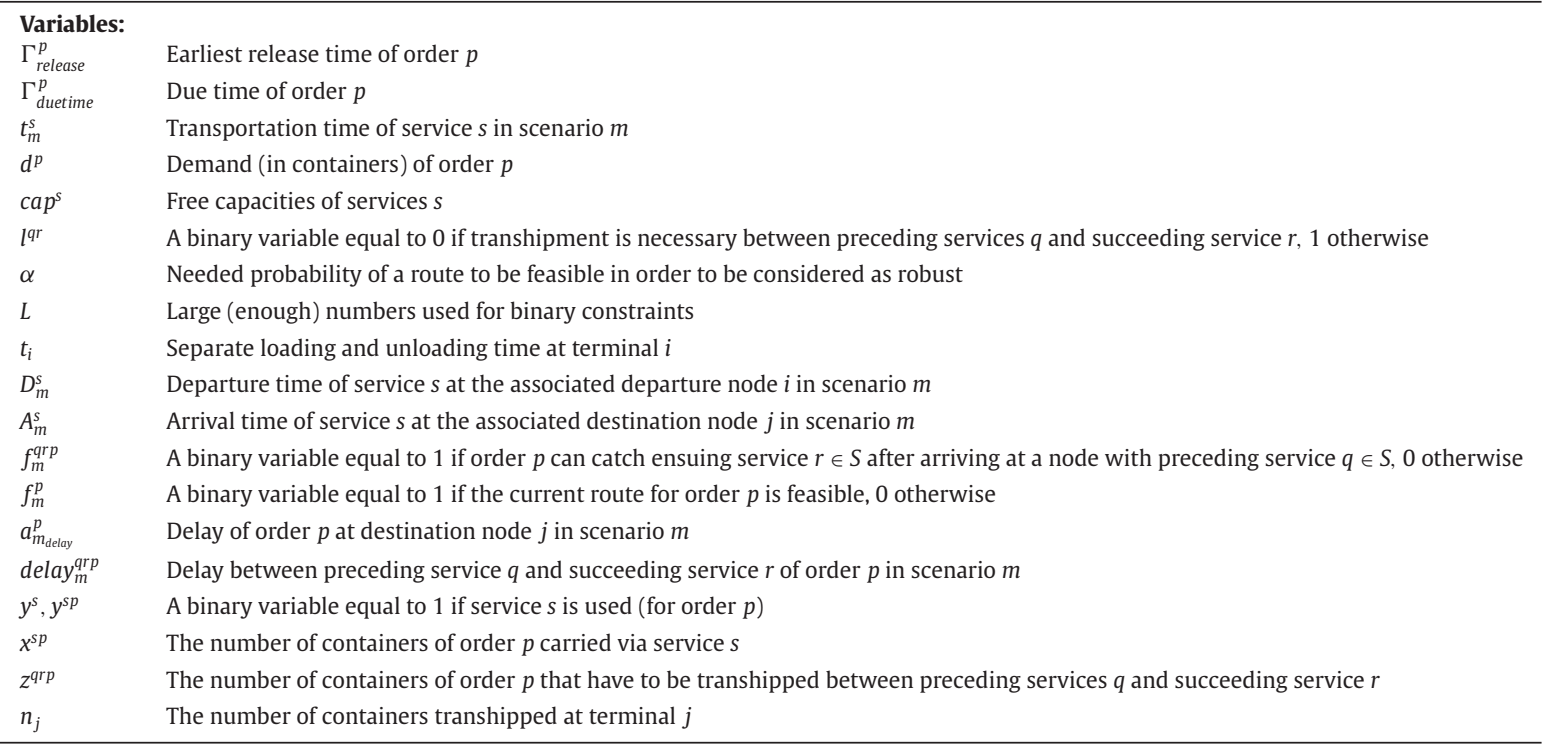

The objective function minimizes the total weighted costs. The weights, thereby, enable the reflection of individual preferences regarding direct transportation, time-related and $\mathrm{CO}_{2} \mathrm{e}$ emissions-related costs. The direct transportation costs consist of transportation costs per container and service $c^{s}$ - which include the fixed transportation costs per service allocated to one container as well as the direct transportation costs per container - and transhipment costs per container $\left(c_{j}\right)$. The time-related costs are represented in a way to allow charges for delayed deliveries $\left(c_{\text {pen }}^{p}\right)$ while the $\mathrm{CO}_{2}$ e emissions-related costs per $\mathrm{kg}\left(c_{e m i}\right)$ for the emissions consumed per container serviced $\left(e^{s}\right)$ and transhipped $\left(e_{j}\right)$ are also included.

$$
\begin{aligned}
& \text { Minimize } \quad \omega_{1}\left\{\sum_{p \in \mathcal{P}} \sum_{s \in \mathcal{S}} x^{s p} c^{s}+\sum_{j \in \mathcal{N}} n_{j} c_{j}\right\} \\
& +\omega_{2} \frac{1}{M} \sum_{m \in \mathcal{M}} \sum_{p \in \mathcal{P}} \sum_{s \in \mathcal{S}} a_{m_{\text {delay }}}^{p} c_{p e n}^{p} \\
& +\omega_{3} c_{\text {emi }}\left\{\sum_{p \in \mathcal{P}} \sum_{s \in \mathcal{S}} x^{s p} e^{s}+\sum_{j \in \mathcal{N}} n_{j} e_{j}\right\}
\end{aligned}
$$

Subject to:

$$
\begin{aligned}
& \sum_{s \in \delta(s \in \mathcal{S} \mid n=i)} x^{s p}=d^{p} \quad \forall n \in \mathcal{N} \mid n=i, \quad p \in \mathcal{P} \\
& \sum_{s \in \delta(s \in \mathcal{S} \mid n=j)} x^{s p}=d^{p} \quad \forall n \in \mathcal{N} \mid n=j, \quad p \in \mathcal{P} \\
& \sum_{s \in \delta(s \in \mathcal{S} \mid n=i)} x^{s p}-\sum_{s \in \delta(s \in \mathcal{S} \mid n=j)} x^{s p}=0 \quad \forall n \in \mathcal{N} \mid(n \neq i \& n \neq j), \quad p \in \mathcal{P} \\
& \sum_{p \in \mathcal{\gamma}(p \in \mathcal{P})} x^{s p}-y^{s} c a p^{s} \leq 0 \quad \forall s \in \delta(s \in \mathcal{S}) \\
& x^{s p} \leq y^{s p} L \quad \forall s \in \delta(s \in \mathcal{S}), \quad p \in \mathcal{\gamma}(p \in \mathcal{P}) \\
& x^{s p} \geq y^{s p} \forall s \in \delta(s \in \mathcal{S}), \quad p \in \gamma(p \in \mathcal{P}) \\
& y^{s} \leq \sum_{p \in \mathcal{\gamma}(p \in \mathcal{P})} x^{s p} \quad \forall s \in \delta(s \in \mathcal{S})
\end{aligned}
$$




$$
\begin{aligned}
& \sum_{p \in \mathcal{P}} \sum_{\delta(s \in \mathcal{S}|i=n| j=n)} x^{s p}-2 \sum_{p \in \mathcal{P}} \sum_{\substack{q \in \\
\delta(q \in \mathcal{S} \mid i=n)}} \sum_{\substack{r \in \mathcal{S} \mid j=n) \\
(r \in \mathcal{S}}} z^{q r p}=n_{n} \quad \forall n \in \mathcal{N} \\
& D_{m}^{S}+t_{m}^{S}-A_{m}^{S} \leq L\left(1-y^{s}\right) \quad \forall s \in \delta(s \in \mathcal{S}), \quad \forall m \in \mathcal{M} \\
& A_{m}^{q}+t_{i} x^{q p}+t_{i} x^{r p}-2 t_{i} z^{q r p}-\text { delay }_{m}^{q r p}-D^{r}-L\left(1-y^{q p}\right) \leq L\left(1-y^{r p}\right) \quad \forall m \in \mathcal{M}, \quad q \in \delta(s \in \mathcal{S} \mid j \in \mathcal{N}),
\end{aligned}
$$

$1-f_{m}^{q r p} \leq \operatorname{delay}_{m}^{q r p} \quad \forall q \in \mathcal{S}, \quad r \in \mathcal{S}, \quad p \in \mathcal{P}, \quad m \in \mathcal{M}$

$L\left(1-f_{m}^{q r p}\right) \geq$ delay $_{m}^{q r p} \quad \forall q \in \mathcal{S}, \quad r \in \mathcal{S}, \quad p \in \mathcal{P}, \quad m \in \mathcal{M}$

$f_{m}^{q r p} \geq f_{m}^{p} \quad \forall q \in \mathcal{S}, \quad r \in \mathcal{S}, \quad p \in \mathcal{P}, \quad m \in \mathcal{M}$

$\sum_{m \in \mathcal{M}} f_{m}^{p} \geq M \alpha \quad \forall p \in \mathcal{P}$

$z^{q r p} \leq L l^{q r} \quad \forall q \in \delta(s \in \mathcal{S} \mid j \in \mathcal{N}), \quad p \in \mathcal{P}, \quad r \in \delta(s \in \mathcal{S} \mid i \in \mathcal{N})$

$D_{m}^{s}-y^{s p} \Gamma_{\text {release }}^{p} \geq 0 \quad \forall m \in \mathcal{M}, \quad p \in \mathcal{P}, \quad s \in \delta\left(s \in \mathcal{S} \mid i \in \mathcal{N}^{+}\right)$

$A_{m}^{s}-a_{m_{\text {delay }}}^{p}-\Gamma_{\text {duetime }}^{p} \leq L\left(1-y^{s p}\right) \quad \forall p \in \mathcal{P}, \quad m \in \mathcal{M}, \quad s \in \delta\left(s \in \mathcal{S} \mid i \in \mathcal{N}^{-}\right)$

$T_{\min }^{s} y^{s} \leq D_{m}^{s} \leq T_{\max }^{s} y^{s} \quad \forall m \in \mathcal{M}, \quad s \in \mathcal{S}$

delay $_{m}^{q r p} \leq y^{q p} L \quad \forall q \in \mathcal{S}, \quad r \in \mathcal{S}, \quad p \in \mathcal{P}, \quad m \in \mathcal{M}$

$\operatorname{delay}_{m}^{q r p} \leq y^{r p} L \quad \forall q \in \mathcal{S}, \quad r \in \mathcal{S}, \quad p \in \mathcal{P}, \quad m \in \mathcal{M}$

$f_{m}^{q r p}, f_{m}^{p}, y^{s}, y^{s p}=\{0,1\} \quad \forall s \in \mathcal{S}, \quad q \in \mathcal{S}, \quad r \in \mathcal{S}, \quad p \in \mathcal{P}, \quad m \in \mathcal{M}$

$$
a_{m_{\text {delay }}}^{p}, x^{s p}, z^{q r p}, \text { delay }_{m}^{q r p}, D^{s}, A_{m}^{s} \geq 0 \quad \forall s \in \mathcal{S}, \quad q \in \mathcal{S}, \quad r \in \mathcal{S}, \quad p \in \mathcal{P}, \quad m \in \mathcal{M}
$$

Constraints (11)-(13) manage the traffic/container flow. While constraints (11) and (12) focus on the origin and destination nodes, constraint (13) manages the transhipment. Demand, in that regard, is positive if more containers are planned to originate from a specific node than are destined for that node. Constraint (14) ensures that capacity limits of services are adhered to. Constraints (15)-(17) make sure that a service is only allowed to process any amount of containers when it is selected. While (18) tracks the transhipment necessary, constraints (19) and (20) ensure the timely sequencing of the services within the network. As seen in (19), each service has interrelated departure, service and arrival times per scenario $m$. In addition to the synchronization at nodes in terms of loading units ((11)-(13)), constraint (20) takes care of the timely synchronization. It ensures the relation of sequential services at a transhipment location. This is necessary due to more or less fixed schedules of services, which permit services with earlier departure times than possible preceding services from following up on them. Thus - for a plan to be feasible in scenario $m$ - the arrival time of the preceding service $(q)$ at a transhipment location plus the necessary unloading and loading times $\left(t_{i} x^{q p}+t_{i} x^{r p}-2 t_{i} z^{q r p}\right)$ have to be fulfilled before the ensuing service $(r)$ departs. In case of an infeasible plan for scenario $m$, constraints (21)-(23) ensure that $f_{m}^{p}$ is 0 . A plan, then, is not robust and thus erased from the possible set of transportation routes in case of more than $1-\alpha$ percent of all scenarios being infeasible (see constraint (24)). Constraint (25) ensures that only containers which have to change the vehicle are considered when calculating transhipment times, costs and $\mathrm{CO}_{2} e$-emissions. Constraints (26) and (27) provide the time frame for each order to plan within. The lower limit (earliest pick-up time) is fixed while the upper limit (due date) can be bent, with penalties - if desired - allocated to late deliveries $\left(a_{m_{\text {delay }}}^{p}\right)$. Constraint (28) gives the time window within which services can depart with $T_{\min }^{s}=T_{\max }^{s}$ being valid for scheduled services. Constraints (29) and (30) ensure that the feasibility of two consecutive services is only checked if these services are designated to be used within the same routing plan. 


\subsection{The sample average approximation method}

Solving stochastic network optimization models by conventional methods such as dynamic programming and multistage stochastic programming is not possible for realistic problem sizes. In this study we apply the SAA method to solve the stochastic network problem with chance constraints.

Kenyon and Morton (2003) apply SAA to solve a stochastic VRP under two different objective functions: minimizing the expected completion time and maximizing the probability of completion time being below a target level. Luedtke and Ahmed (2008) provide an application of SAA to a chance-constrained transportation problem with a convex feasible region where the dimension of the random vector presents a computational challenge. Wang and Meng (2012) apply SAA for a schedule design problem for liner shipping services to minimize expected costs and Wang et al. (2013) apply it to chance-constrained liner ship fleet deployment problem. The approximation is obtained by replacing the actual distribution with an empirical distribution by Monte Carlo sampling. If the objective function corresponds to an expected value it is approximated by its sample average estimate. The resulting problem is then solved by deterministic optimization methods. Verweij et al. (2003) provide an introduction to the application of SAA to stochastic routing problems with expected value objectives.

In a chance-constrained problem the method is used to approximate the true probability of the constrained event by its frequency of occurrence within the sample. In general, SAA is applied to chance-constrained stochastic problems because of two reasons: the feasible region defined by the chance constraint can be non-convex, and the probability of the constrained event may be difficult to evaluate (Luedtke and Ahmed, 2008; Pagnoncelli et al., 2009). It has been shown that the optimal solution of the sampled problem converges exponentially fast to the optimal solution of the original problem as the number of scenarios increases. The solution of the sampled problem can be used to develop statistical bounds on the optimal solution of the original problem.

In this methodology, we generate $K$ independent samples where each sample includes $M$ realizations of service times $t^{s}$ according to the probability distributions $\pi^{s}$. We solve the model for each sample $k \in K$ separately to obtain the objective value $C_{k}$ and the corresponding solution $\theta_{k}$. In order to decide which of the $K$ solutions to select, an independent test sample is generated to evaluate each candidate solution $\theta_{k}$. The test sample with size $M^{\prime}$ is generally chosen to be quite large. Using the test sample, each solution $\theta_{k}$ is evaluated to obtain the probability of replanning. If a solution has a higher probability than $1-\alpha$ it is not considered as a feasible solution. Otherwise it is a candidate solution. We select the best candidate solution with the minimum cost under $M^{\prime}$ as the optimal solution $\theta^{*}$ to the problem. For any feasible solution $\theta$ the objective function value under any independent sample $C(\theta)$ is an upper bound for the true objective value. Therefore the upper bound corresponding to $\theta^{*}$ is calculated as

$$
U B=C_{M^{\prime}}\left(\theta^{*}\right)+\frac{z_{\beta} \sigma_{U}}{\sqrt{M^{\prime}}},
$$

where $z_{\beta}$ is the $1-\beta$ quantile of the standard normal distribution and $\sigma_{U}$ is the standard deviation of the objective value within the test sample.

In order to evaluate the quality of the solution we derive a lower bound as described by Luedtke and Ahmed (2008). The $K$ optimal values corresponding to different samples are rearranged to obtain the order statistics $C_{[k]}$ for $k=1, \ldots, K$ such that $C_{[1]} \leq \ldots \leq C_{[K]}$. The $L$ th order statistic $C_{[L]}$ corresponds to a lower bound with a confidence level of $\gamma$ where

$$
\gamma=\sum_{i=0}^{L-1}\left(\begin{array}{c}
K \\
i
\end{array}\right) \rho(\alpha, M)^{i}(1-\rho(\alpha, M))^{K-i},
$$

and

$$
\rho(\alpha, M)=\sum_{i=0}^{\lfloor\alpha M\rfloor}\left(\begin{array}{c}
M \\
i
\end{array}\right) \alpha^{i}(1-\alpha)^{M-i} .
$$

The quality of the solution $\theta^{*}$ is evaluated based on the optimality gap estimate $(U B-L B) / L B$. The sample sizes are selected to ensure a reasonable optimality gap, e.g. smaller than $1 \%$.

\subsection{Extension to the demand uncertainty}

As mentioned in Section 2, the inclusion of demand uncertainties in routing and even SND problems is more common. Therefore we have focused our central approach - as seen in Section 4.1 - on travel time uncertainties. Nevertheless, demand uncertainties are important to reflect.

In order to also use SAA as the approach to include demand uncertainties, a set of scenarios taken from depicted demand distribution functions is necessary $(k \in \mathcal{K})$. Thereby, it's essential to enable the booking/canceling of unexpected higher/lower demand $\left(b_{k}^{s p}\right)$ either on - if possible - free capacity slots or on other services $\left(o c a p_{k}^{s}\right)$ in order to account for possibly varying demand over all $K$-scenarios $\left(d_{k}^{p}\right)$. These extensions especially are to be reflected in constraints (11)-(14) which focus on demand fulfillment and capacity restriction. 


$$
\begin{aligned}
& \text { Minimize } \omega_{1}\left\{\sum_{p \in \mathcal{P}} \sum_{s \in \mathcal{S}} x^{s p} c^{s}+\frac{1}{K} \sum_{p \in \mathcal{P}} \sum_{s \in \mathcal{S}} \sum_{k \in \mathcal{K}} b_{k}^{s p} c^{s}+\sum_{j \in \mathcal{N}} n_{j} c_{j}+\frac{1}{K} \sum_{s \in \mathcal{S}} \sum_{k \in \mathcal{K}} \text { ocap }_{k}^{s} c_{p e n_{d}}^{s}\right\} \\
& +\omega_{2} \frac{1}{M} \sum_{m \in \mathcal{M}} \sum_{p \in \mathcal{P}} \sum_{s \in \mathcal{S}} a_{m_{\text {delay }}^{p}} c_{\text {pen }}^{p} \\
& +\omega_{3} c_{\text {emi }}\left\{\sum_{p \in \mathcal{P}} \sum_{s \in \mathcal{S}} x^{s p} e^{s}+\frac{1}{K} \sum_{p \in \mathcal{P}} \sum_{s \in \mathcal{S}} \sum_{k \in \mathcal{K}} b_{k}^{s p} e^{s}+\sum_{j \in \mathcal{N}} n_{j} e_{j}\right\}
\end{aligned}
$$

Subject to:

$$
\begin{aligned}
& \sum_{s \in \delta(s \in \mathcal{S} \mid n=i)}\left\{x^{s p}+b_{k}^{s p}\right\}=d_{k}^{p} \quad \forall n \in \mathcal{N} \mid n=i, \quad p \in \mathcal{P}, \quad k \in \mathcal{K} \\
& \sum_{s \in \delta(s \in \mathcal{S} \mid n=j)}\left\{x^{s p}+b_{k}^{s p}\right\}=d_{k}^{p} \quad \forall n \in \mathcal{N} \mid n=j, \quad p \in \mathcal{P}, \quad k \in \mathcal{K} \\
& \sum_{s \in \delta(s \in \mathcal{S} \mid n=i)}\left\{x^{s p}+b_{k}^{s p}\right\}-\sum_{s \in \delta(s \in \mathcal{S} \mid n=j)}\left\{x^{s p}+b_{k}^{s p}\right\}=0 \quad \forall n \in \mathcal{N} \mid(n \neq i \& n \neq j), \quad p \in \mathcal{P}, \quad k \in \mathcal{K} \\
& \sum_{p \in \mathcal{\gamma}(p \in \mathcal{P}, i, j)}\left\{x^{s p}+b_{k}^{s p}\right\}-y^{s} c a p^{s}-o c a p_{k}^{s} \leq 0 \quad \forall s \in \delta(s \in \mathcal{S}, i, j), \quad k \in \mathcal{K}
\end{aligned}
$$

and constraints (15)-(32).

The objective function (36) contains costs for possibly additional needed capacity $\left(c_{\text {pen }}^{s}\right)$ as well as costs for additional/substracted containers transported with the already planned-for capacity $\left(c^{s}\right)$. These cost factors, thereby, are counted for each scenario and therefore have to be divided by K. Constraints (39)-(41) are constraints (11)-(13) with the necessary additions for the inclusion of demand uncertainties. They are extended by $b_{k}^{s p}$ in order to reflect a possible difference in actual demand compared to the planned for demand. Constraint (42) makes sure that all ordered containers which cannot be fulfilled by the selected service $\left(c a p^{S}\right)$ have to be transported by another service and thus accounted for in the objective function (ocap $p_{k}^{s}$.

\section{Case study/Application}

In order to test the behavior of the methodology and to compare the results using different weights for the individual objectives, a realistic case study was studied including road, rail and inland waterway transportation as the main transportation modes used in hinterland transportation chains bringing containers from and to the main European ports. The case study is described in this section whereas the results of an extensive computational study including instances with higher number of nodes, services and orders are presented in Section 6.

The case study is concentrated on the Danube region between Hungary and Germany which serves as destination and origin of containerized goods coming from maritime transportation (via donau, 2006). There exist a number of intermodal terminals from which containers are transported by feeder services to bigger terminals in Germany, Austria or Czech Republic. These terminals then have direct connection to the maritime ports in Germany, the Netherlands or Belgium.

The network consists of 10 terminals including inland waterway ports and railway terminals which are connected by 32 services. Each of the terminals is characterized by the time, costs and emissions needed for transhipment of one container whereas each service is defined by its origin, destination, distance, vehicle, capacity, time window for departure $\left(T_{\text {min }}^{s}\right.$, $T_{\text {max }}^{s}$ ), travel time, transportation costs and emissions. The terminals and services are depicted in Fig. 2 and the characteristics of the services are described in Table 1.

Since the region is located around the Danube, a container transportation by ship connecting the terminals in Budapest, Vienna, Linz and Regensburg is modeled as three consecutive services operated by one ship so that the next service can start only after the previous service's arrival to the terminal. This offers the advantage for the containers which can be transported directly from Budapest to Regensburg, but also additional freight can be loaded on the ship if there is free capacity left. The costs and travel times for the ship were derived from via donau (2007) and the capacity was set to 60 twenty-foot equivalent units (TEU). The ship services are displayed in Table 1 as services $1-3$.

The inland waterway network was enhanced by railway terminals in Budapest, Vienna, Prague, Wels, Salzburg and Munich which are connected by multiple trains per week or even per day. Trains depart at fixed times according to time schedules which are publicly available. In this case study, rail transportation is modeled in form of services with fixed time windows for departure according to schedules published by Metrans (2014) and Kombiverkehr (2014). The time frame used for departures was one week which means that there can be multiple services between the same terminals. Since the train capacity is partly blocked by existing agreements with logistics service providers, an average train with 750 tons net weight and utilization of $80 \%$ is used for 


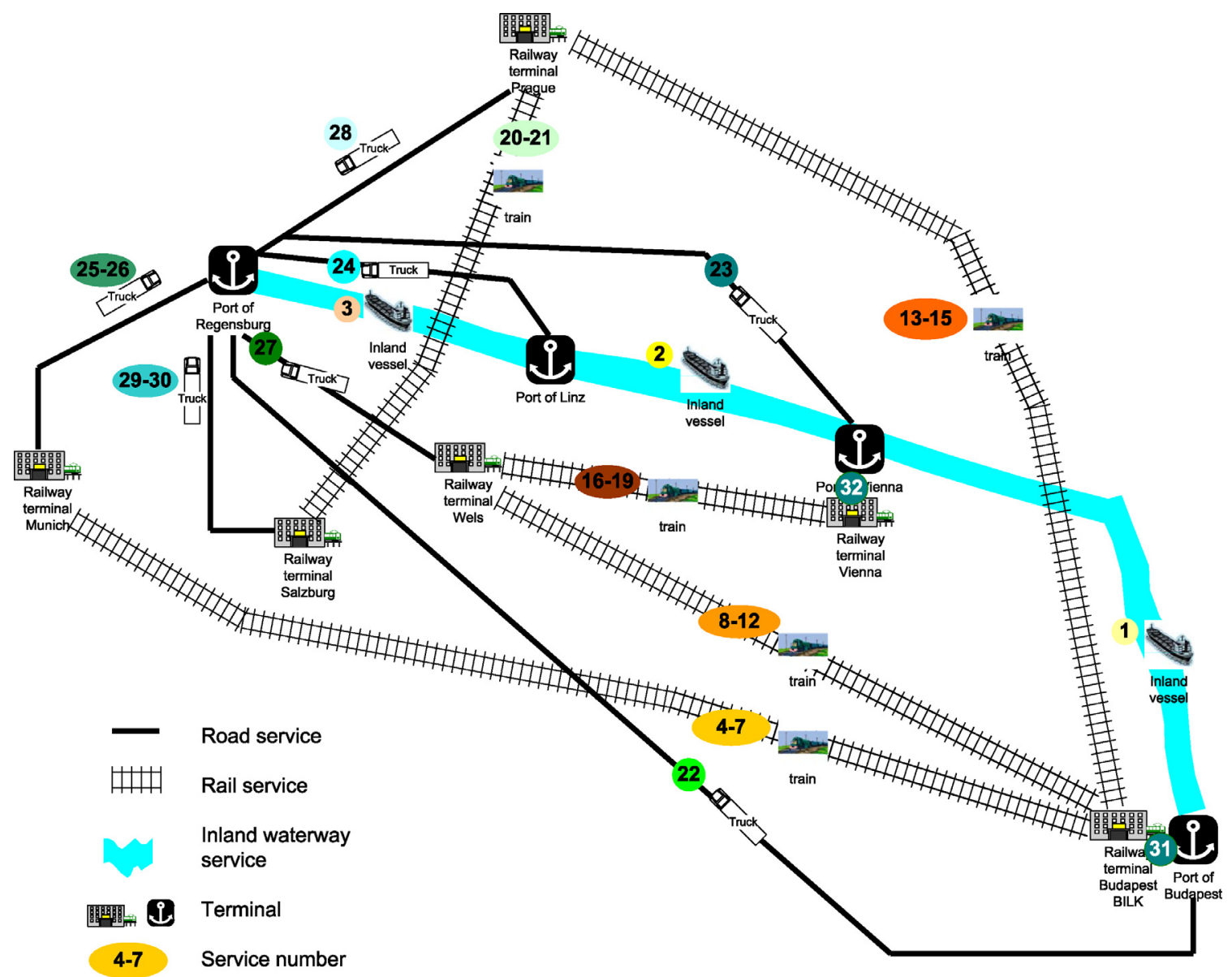

Fig. 2. A visualization of services used in the case study.

calculations (PLANCO, 2007). The remaining capacity is used for the new orders. The fixed costs for train, personnel and other variable costs (i.e., energy and infrastructure fees) were calculated based on PLANCO (2007). Train services have numbers 4-21 in Table 1.

Transportation by truck is relatively flexible regarding the departure time and route since trucks do not need to run according to fixed schedules but can be booked when they are needed. Therefore, flexible time windows for departure and high available capacities are assumed so that every order which arrives can be transported by a truck. The travel times and costs were calculated using the Map\&Guide tool from PTV (2014). Trucks are represented by services 22-32 in Table 1.

The transport orders are displayed in Table 2. Thereby, more than one order is chosen in order to show and test the ability of the model to consolidate orders.

For the computational analysis we first use the deterministic travel times while comparing them to the stochastic ones. Thereby we assume a three point distribution for each travel time. The three possible realizations correspond to (i) the most likely service time which is the one used in deterministic models and is also displayed in Table 1, (ii) the service time under congestion, and (iii) the service time under disruption. In order to evaluate the robustness and feasibility of a route, we set $\alpha=0.95$ meaning that the route is only used if it is feasible in at least $95 \%$ of the scenarios. We also used nine different weight combinations in order to see the impact of the direct service costs $\left(w_{1}\right)$, time penalty costs $\left(w_{2}\right)$ and emission-related costs $\left(w_{3}\right)$ on the results.

For the stochastic problem, we set $M=50$ and we varied $L$ so that we find a valid lower bound with confidence 0.99 . Similarly for the upper bound calculation we used a sample size of $M^{\prime}=5000$ for the test sample and we applied $\beta=0.99$ so that we reach a confidence level of 0.99 . For all the different weight combinations, these parameters guarantee an optimality gap for the objective function value within $1 \%$ which implies that the quality of the approximation is satisfactory (see, e.g., Kenyon and Morton, 2003; Verweij et al., 2003; Wang et al., 2013).

As the deterministic results presented in Table 3 show, the optimal solution is strongly dependent on the weights for each objective. In cases where the relative weight of the direct service costs is reasonably high (cases 1, 4, 6 and 8), the model tries to choose rail and inland waterway as cheaper transportation modes instead of road. This also has positive impact on emissions 
Table 1

A detailed information for services used in the case study.

\begin{tabular}{|c|c|c|c|c|c|c|c|c|c|}
\hline $\begin{array}{l}\text { Service } \\
\text { number }\end{array}$ & Origin & Destination & $\begin{array}{l}\text { Distance } \\
\text { in } \mathbf{~ k m}\end{array}$ & $\begin{array}{l}\text { Capacity } \\
\text { in TEU }\end{array}$ & $T_{\min }^{s}$ & $T_{\max }^{s}$ & $\begin{array}{l}\text { Costs } \\
\text { in } €\end{array}$ & $\begin{array}{l}\text { Emissions } \\
\text { in } \mathrm{kg}\end{array}$ & $\begin{array}{l}\text { Time } \\
\text { in hours }\end{array}$ \\
\hline 1 & Budapest Port & Vienna Port & 280 & 60 & 32 & 32 & 115 & 127 & 42 \\
\hline 2 & Vienna Port & Linz & 211 & 60 & 76 & 97 & 63 & 53 & 29 \\
\hline 3 & Linz & Regensburg & 242 & 42 & 107 & 141 & 102 & 86 & 49 \\
\hline 4 & Budapest BILK & Munich & 729 & 20 & 18 & 18 & 182 & 70 & 38 \\
\hline 5 & Budapest BILK & Munich & 729 & 20 & 42 & 42 & 181 & 69 & 84 \\
\hline 6 & Budapest BILK & Munich & 729 & 20 & 114 & 114 & 183 & 71 & 38 \\
\hline 7 & Budapest BILK & Munich & 729 & 20 & 162 & 162 & 184 & 68 & 38 \\
\hline 8 & Budapest BILK & Wels & 488 & 16 & 21 & 21 & 201 & 50 & 35 \\
\hline 9 & Budapest BILK & Wels & 488 & 16 & 45 & 45 & 202 & 49 & 58 \\
\hline 10 & Budapest BILK & Wels & 488 & 16 & 117 & 117 & 200 & 51 & 35 \\
\hline 11 & Budapest BILK & Wels & 488 & 16 & 141 & 141 & 203 & 48 & 35 \\
\hline 12 & Budapest BILK & Wels & 488 & 16 & 165 & 165 & 199 & 52 & 35 \\
\hline 13 & Budapest BILK & Prague & 626 & 16 & 8 & 8 & 250 & 163 & 40 \\
\hline 14 & Budapest BILK & Prague & 626 & 16 & 80 & 80 & 251 & 162 & 40 \\
\hline 15 & Budapest BILK & Prague & 626 & 16 & 128 & 128 & 249 & 164 & 40 \\
\hline 16 & Vienna Rail & Wels & 218 & 16 & 19 & 19 & 113 & 9 & 11 \\
\hline 17 & Vienna Rail & Wels & 218 & 16 & 115 & 115 & 114 & 8 & 11 \\
\hline 18 & Vienna Rail & Wels & 218 & 16 & 139 & 139 & 112 & 10 & 11 \\
\hline 19 & Vienna Rail & Wels & 218 & 16 & 163 & 163 & 115 & 11 & 11 \\
\hline 20 & Prague & Salzburg & 415 & 16 & 17 & 17 & 109 & 53 & 81 \\
\hline 21 & Prague & Salzburg & 415 & 16 & 137 & 137 & 110 & 52 & 35 \\
\hline 22 & Budapest Port & Regensburg & 649 & 60 & 0 & 168 & 484 & 390 & 10 \\
\hline 23 & Vienna Port & Regensburg & 404 & 60 & 0 & 168 & 327 & 252 & 6 \\
\hline 24 & $\operatorname{Linz}$ & Regensburg & 231 & 60 & 0 & 168 & 196 & 140 & 3 \\
\hline 25 & Munich & Regensburg & 136 & 60 & 0 & 168 & 129 & 83 & 2 \\
\hline 26 & Regensburg & Munich & 136 & 60 & 0 & 168 & 129 & 83 & 2 \\
\hline 27 & Wels & Regensburg & 203 & 60 & 0 & 168 & 165 & 123 & 3 \\
\hline 28 & Prague & Regensburg & 249 & 60 & 0 & 168 & 209 & 158 & 4 \\
\hline 29 & Salzburg & Regensburg & 229 & 60 & 0 & 168 & 193 & 157 & 4 \\
\hline 30 & Regensburg & Salzburg & 229 & 60 & 0 & 168 & 193 & 157 & 4 \\
\hline 31 & Budapest Port & Budapest BILK & 11 & 60 & 0 & 168 & 62 & 14 & 0 \\
\hline 32 & Vienna Port & Vienna Rail & 12 & 60 & 0 & 168 & 66 & 12 & 0 \\
\hline
\end{tabular}

Table 2

A detailed information on the orders considered in the case study.

\begin{tabular}{lllllcr}
\hline $\begin{array}{l}\text { Order } \\
\text { number }\end{array}$ & From & To & $\begin{array}{l}\text { Release time } \\
\text { in hours }\end{array}$ & $\begin{array}{l}\text { Due time } \\
\text { in hours }\end{array}$ & $\begin{array}{l}\text { Number of containers } \\
\text { in TEU }\end{array}$ & $\begin{array}{l}\text { Penalty costs } \\
\text { per hour }\end{array}$ \\
\hline 1 & Budapest Port & Regensburg & 10 & 160 & 20 & 30 \\
2 & Budapest Port & Regensburg & 25 & 170 & 10 & 100 \\
3 & Budapest Port & Munich & 20 & 80 & 15 & 70 \\
4 & Vienna Port & Regensburg & 70 & 159 & 9 & 80 \\
5 & Prague & Salzburg & 30 & 102 & 6 & 50 \\
\hline
\end{tabular}

Table 3

Results for the deterministic setting.

\begin{tabular}{|c|c|c|c|c|c|c|c|c|c|c|c|c|}
\hline \multirow[t]{2}{*}{ Case } & \multicolumn{3}{|c|}{ Weights } & \multicolumn{5}{|c|}{ Optimal services } & \multirow{2}{*}{$\begin{array}{l}\text { Total service } \\
\text { costs }(€)\end{array}$} & \multirow{2}{*}{$\begin{array}{l}\text { Total penalty } \\
\text { costs }(€)\end{array}$} & \multirow{2}{*}{$\begin{array}{l}\text { Total emissions } \\
\text { costs }(€)\end{array}$} & \multirow{2}{*}{$\begin{array}{l}\text { Total } \\
\text { costs }(€)\end{array}$} \\
\hline & $w_{1}$ & $w_{2}$ & $w_{3}$ & 1 & 2 & 3 & 4 & 5 & & & & \\
\hline 1 & 1 & 0 & 0 & $1,2,3$ & $1,2,3$ & 31,5 & 2,3 & 21 & 17,179 & 6,720 & 782 & 24,681 \\
\hline 2 & 0 & 1 & 0 & 22 & 22 & 22,26 & 23 & 28,30 & 32,284 & 0 & 1,634 & 33,919 \\
\hline 3 & 0 & 0 & 1 & $31,5,25$ & $31,6,25$ & 31,7 & 2,3 & 21 & 22,435 & 12,200 & 594 & 35,229 \\
\hline 4 & 0.4 & 0.4 & 0.2 & $1,2,3$ & $1,2,3$ & 31,5 & 2,3 & 28,30 & 19,171 & 3,220 & 894 & 23,285 \\
\hline 5 & 0.2 & 0.6 & 0.2 & $1,2,3$ & $1,2,3$ & 22,26 & 2,3 & 28,30 & 24,707 & 0 & 1,303 & 26,010 \\
\hline 6 & 0.6 & 0.3 & 0.1 & $1,2,3$ & $1,2,3$ & 31,5 & 2,3 & 21 & 17,179 & 6,720 & 782 & 24,681 \\
\hline 7 & 0.1 & 0.8 & 0.1 & $1,2,3$ & $1,2,3$ & 22,26 & 2,3 & 28,30 & 24,707 & 0 & 1,303 & 26,010 \\
\hline 8 & 1 & 1 & 1 & $1,2,3$ & $1,2,3$ & 31,5 & 2,3 & 28,30 & 19,171 & 3,220 & 894 & 23,285 \\
\hline 9 & 1 & 10 & 10 & $1,2,3$ & $1,2,3$ & $31,8,27,26$ & 2,3 & 28,30 & 25,081 & 0 & 1,098 & 26,179 \\
\hline
\end{tabular}


Table 4

Results for the stochastic setting.

\begin{tabular}{|c|c|c|c|c|c|c|c|c|c|c|c|c|c|c|}
\hline \multirow[t]{2}{*}{ Case } & \multicolumn{3}{|c|}{ Weights } & \multicolumn{5}{|c|}{ Optimal services } & \multirow{2}{*}{$\begin{array}{l}\text { Total service } \\
\text { costs }\end{array}$} & \multicolumn{2}{|c|}{ Total penalty costs } & \multirow{2}{*}{$\begin{array}{l}\text { Total emissions } \\
\text { costs }\end{array}$} & \multicolumn{2}{|c|}{ Total costs } \\
\hline & $w_{1}$ & $w_{2}$ & $w_{3}$ & 1 & 2 & 3 & 4 & 5 & & LB & UB & & LB & UB \\
\hline 1 & 1 & 0 & 0 & $1,2,3$ & $1,2,3$ & 31,5 & 2,3 & 21 & 17,179 & 7,575 & 7,646 & 782 & 25,536 & 25,607 \\
\hline 2 & 0 & 1 & 0 & 22 & 22 & 22,26 & 23 & 28,30 & 32,284 & 0 & 0 & 1,634 & 33,919 & 33,919 \\
\hline 3 & 0 & 0 & 1 & $31,5,25$ & $31,9,27$ & 31,7 & 2,3 & 21 & 22,984 & 12,396 & 12,522 & 605 & 35,985 & 36,111 \\
\hline 4 & 0.4 & 0.4 & 0.2 & $1,2,3$ & $1,2,3$ & 31,5 & 2,3 & 28,30 & 19,171 & 3,945 & 4,038 & 894 & 24,010 & 24,103 \\
\hline 5 & 0.2 & 0.6 & 0.2 & $1,2,3$ & $1,2,3$ & 22,26 & 2,3 & 28,30 & 24,707 & 225 & 525 & 1,303 & 26,235 & 26,535 \\
\hline 6 & 0.6 & 0.3 & 0.1 & $1,2,3$ & $1,2,3$ & 31,5 & 2,3 & 21 & 17,179 & 7,575 & 7,646 & 782 & 25,536 & 25,607 \\
\hline 7 & 0.1 & 0.8 & 0.1 & $1,2,3$ & $31,5,25$ & 22,26 & 2,24 & 28,30 & 27,696 & 123 & 136 & 1,274 & 29,093 & 29,106 \\
\hline 8 & 1 & 1 & 1 & $1,2,3$ & $1,2,3$ & 31,5 & 2,3 & 28,30 & 19,171 & 3,945 & 4,038 & 894 & 24,010 & 24,103 \\
\hline 9 & 1 & 10 & 10 & $31,5,25,9,27$ & $31,5,25$ & 22,26 & 2,24 & 28,30 & 31,726 & 0 & 16 & 1,162 & 32,888 & 32,905 \\
\hline
\end{tabular}
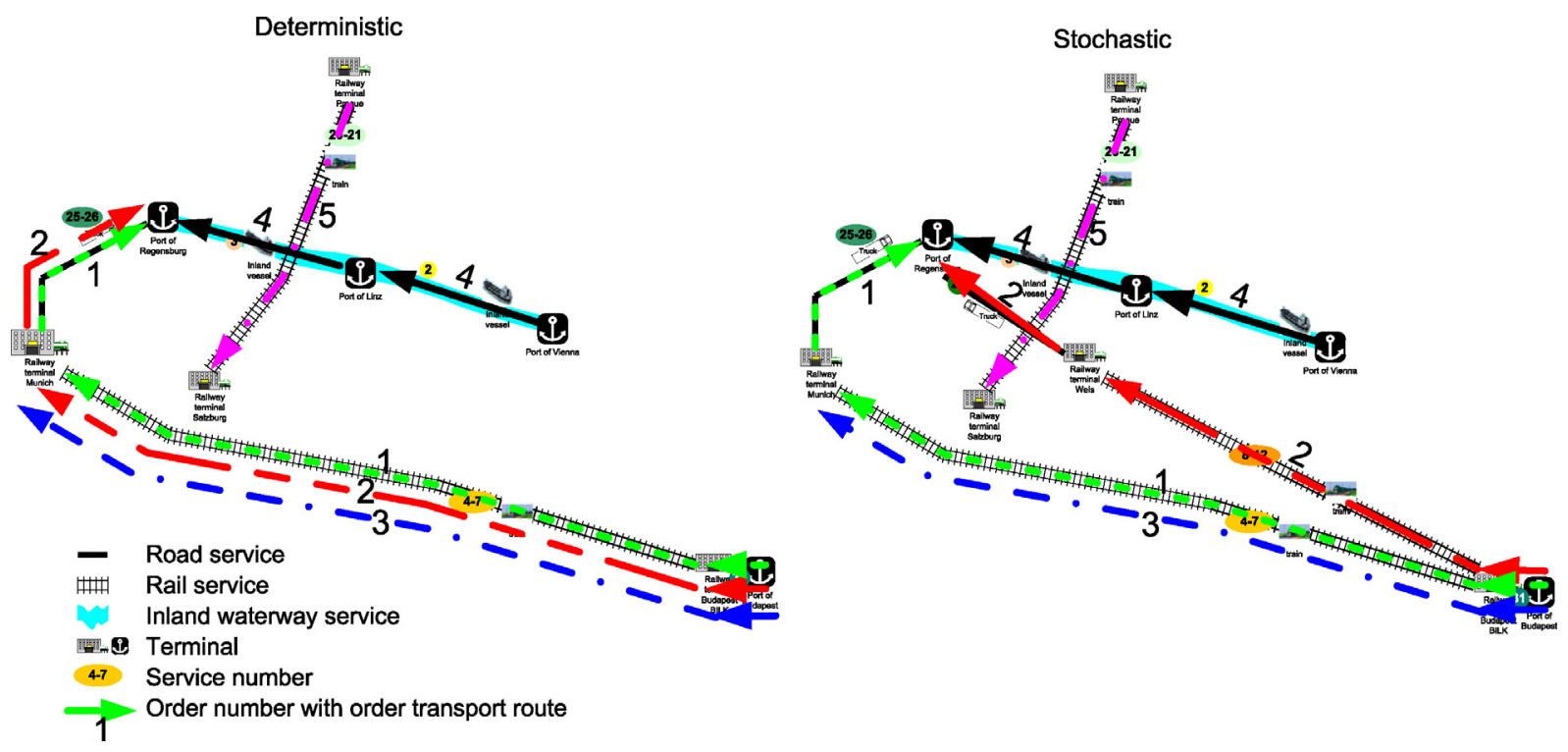

Fig. 3. Comparison of deterministic and stochastic solutions for weights $0,0,1$ (Case 3 ).

which are relatively low, but the longer transportation times by train and ship lead to delays which result in high penalty costs. However, if only or mostly time is considered (especially case 2, but also cases 5 and 7), then the fastest truck connections are chosen and transportation costs as well as emissions are very high. For case 3 where only emissions are important, the orders are transported by electric trains as much as possible which causes delay for order 3 because of the insufficient capacity on the link Budapest-Munich and for order 5 which has to wait for the late train between Prague and Salzburg instead of using trucks. Therefore, the total costs are much higher since the lower emission costs are overcompensated by high transportation and penalty costs.

The total costs are the lowest in two cases (4 and 8) where all three objectives are considered with nearly even weights. Thereby, the focus is on cheap and environmentally friendly transportation modes (inland waterway) while also using the truck for orders which would lead to high time penalty costs (see order 5 in these cases). This balance distinguishes these solutions from e.g. service cost only solutions as seen in case 1 . Overall, the results for all set combinations with a significant weight factor for $w_{1}$ tend to be fairly equal since the direct service costs dominate in absolute magnitude over time penalty and emissionrelated costs. Only cases 2,3 and to some extent 9 with relative high factors of $w_{2}$ and $w_{3}$ compared to $w_{1}$ lead to considerably different results. The results of the stochastic version including variable transportation times are displayed in Table 4 .

As the results show, in 6 of 9 cases the optimal solution does not change. The only differences are not coincidentally in cases 3,7 and 9 as these cases have comparably high weights for time penalties and/or emissions. In case 3 the deterministic solution is not robust enough due to the high number of scenarios in which service 6 arrives too late so that order 2 cannot be transported by service 25. The route is only feasible in $93 \%$ of the scenarios which is below the assumed threshold of $\alpha=0.95$. Therefore the route for order 2 changes to services 31, 9 and 27 where the probability of arriving on-time and using the consecutive service is much higher although the transportation costs and emissions are increasing too. The difference between the deterministic and stochastic solution for this case is graphically represented in Fig. 3. In cases 7 and 9, the original deterministic solution is still feasible, however, when testing it in the stochastic setting, penalty costs for delayed arrival appear. So would the objective function value of the deterministic solution of case 7 in the stochastic setting increase from 2,601 to 3,121. Therefore orders 2 and 
Table 5

Results for the stochastic setting $(n=20, s=50, p=5)$.

\begin{tabular}{|c|c|c|c|c|c|c|c|c|c|c|c|c|c|c|}
\hline \multirow[t]{2}{*}{ Case } & \multicolumn{3}{|c|}{ Weights } & \multicolumn{5}{|c|}{ Optimal services } & \multirow{2}{*}{$\begin{array}{l}\text { Total transportation } \\
\text { costs }\end{array}$} & \multicolumn{2}{|c|}{ Total penalty costs } & \multirow{2}{*}{$\begin{array}{l}\text { Total emissions } \\
\text { costs }\end{array}$} & \multicolumn{2}{|c|}{ Total costs } \\
\hline & $w_{1}$ & $w_{2}$ & $w_{3}$ & 1 & 2 & 3 & 4 & 5 & & LB & UB & & LB & UB \\
\hline 1 & 1 & 1 & 1 & $2,48,13$ & 2,48 & 49 & 2 & 17 & 16,203 & 2,199 & 2,255 & 300 & 18,702 & 18,759 \\
\hline 2 & 1 & 0 & 0 & $2,48,13$ & 2,48 & 49 & 2 & 17 & 16,203 & 2,199 & 2,255 & 300 & 18,702 & 18,759 \\
\hline 3 & 0 & 1 & 0 & $45,16,17$ & 2,48 & 49 & 2 & 17 & 19,023 & 249 & 309 & 160 & 19,432 & 19,492 \\
\hline 4 & 0 & 0 & 1 & $45,16,17$ & 2,48 & 49 & 2 & 17 & 19,023 & 249 & 309 & 160 & 19,432 & 19,492 \\
\hline
\end{tabular}

Table 6

The influence of robustness level $\alpha$ on the computational times and the solution quality.

\begin{tabular}{|c|c|c|c|c|c|c|c|c|c|c|c|}
\hline \multirow[t]{2}{*}{ Instance } & \multirow[t]{2}{*}{ Sample size } & \multicolumn{2}{|c|}{ Deterministic } & \multicolumn{2}{|c|}{ Stochastic $(\alpha=0.75)$} & \multicolumn{2}{|c|}{ Stochastic $(\alpha=0.90)$} & \multicolumn{2}{|c|}{ Stochastic $(\alpha=0.95)$} & \multicolumn{2}{|c|}{ Stochastic $(\alpha=1)$} \\
\hline & & $\begin{array}{l}\text { Objective } \\
\text { value }(€)\end{array}$ & $\begin{array}{l}\text { CPU } \\
(\mathrm{s})\end{array}$ & $\begin{array}{l}\text { Objective } \\
\text { value }(€)\end{array}$ & $\begin{array}{l}\text { CPU } \\
(\mathrm{s})\end{array}$ & $\begin{array}{l}\text { Objective } \\
\text { value }(€)\end{array}$ & $\begin{array}{l}\text { CPU } \\
(s)\end{array}$ & $\begin{array}{l}\text { Objective } \\
\text { value }(€)\end{array}$ & $\begin{array}{l}\text { CPU } \\
(\mathrm{s})\end{array}$ & $\begin{array}{l}\text { Objective } \\
\text { value }(€)\end{array}$ & $\begin{array}{l}\text { CPU } \\
(\mathrm{s})\end{array}$ \\
\hline EU_20_1a_100 & 100 & $1,774.02$ & 0.27 & $1,774.86$ & 320.44 & $1,774.86$ & 320.44 & $1,774.86$ & 243.35 & $1,774.86$ & 3.76 \\
\hline EU_20_1b_100 & 100 & $1,595.45$ & 0.25 & $1,595.45$ & 303.90 & $1,595.45$ & 313.08 & $1,595.45$ & 259.75 & $1,595.45$ & 3.60 \\
\hline EU_20_1c_100 & 100 & $3,563.68$ & 0.26 & $3,563.68$ & 312.93 & $3,563.68$ & 326.76 & $6,519.62$ & 258.98 & $6,519.62$ & 4.24 \\
\hline EU_20_1d_100 & 100 & $3,354.09$ & 0.30 & $3,354.09$ & 328.07 & $4,089.75$ & 362.43 & $4,531.20$ & 256.53 & $4,531.20$ & 3.54 \\
\hline EU_20_1e_100 & 100 & 746.57 & 0.29 & 746.57 & 323.06 & 746.57 & 325.63 & 746.57 & 228.08 & 746.57 & 3.60 \\
\hline
\end{tabular}

4 with high penalty costs per hour are re-routed so that their probability of on-time arrival is increased. The objective function value of this solution (LB: 2,995, UB: 3,005) compares favorably to the deterministic solution. The same reasoning applies to orders 1 to 4 of case 9 .

\section{Computational study}

Besides the case study in Section 5, additional instances have been created to evaluate the capabilities of the methodology to solve larger instances. The basis for the instances presented in this section is a network with 20 locations (or nodes) and the instances vary with respect to the number of services, the number of orders and the level of uncertainty. In most cases the results are available for weights $(1,1,1)$ including all three components of the objective function with the same weight. The objective of the computational study is mainly to show the impact of the different factors on the computational time and the size of the instances which can be solved to optimality. In addition, the solution quality of these instances is also examined for specific cases.

The mixed-integer linear programming model is solved by a standard linear programming solver, namely CPLEX 12.4 (IBM ILOG, 2015). All experiments are conducted on an Intel(R) Core(TM)2 CPU with $2.6 \mathrm{GHz}$ and 3 GB of memory. For the experiments, we use newly generated instances based on real data. These instances follow a naming convention of $E U \_n \_p \_s$ where $E U$ represents the geographical locations of the services and terminals and $n$ is the number of terminals. Moreover, $p$ is the number of orders that need to be transported, and $s$ is the number of services considered (road, rail, and inland waterway). The complete data set used in this paper is available at www.smartlogisticslab.nl.

When we enlarge the network by adding services, the feasible region is obviously larger and the costs would be smaller than or equal to the one under the smaller network. For example, when $n=10$ and $p=1$, with a network of 50 services the order is transported by two consecutive services $(1,50)$ with a cost of $€ 7,470$ in the deterministic setting. When the network is extended to 250 services, a direct service (65) is used which reduces the cost to $€ 6,291$.

Similar effects are seen with respect to the reliability of the plan and the quality of the results under the stochastic environment. The proposed methodology can produce feasible solutions for all the instances as long as an instance can be solved with stochastic travel times. Feasibility here implies that at least one solution satisfies the upper limit on the probability of missing a service, i.e., replanning, within the test sample. However, for large problems, the quality of the solutions decreases significantly. For example, when $n=20, s=50$, and $p=5$, (see Table 5 ) the optimality gap under weight set $(0,1,0)$ is larger than $20 \%$ which cannot be considered in any case. In this specific example, the size of the confidence interval is mainly determined by the variance in transportation time of the first order with services $(45,16,17)$. When we extend the network to 100 services, it is found to be an optimal solution for transporting the first order via a direct service (60) which decreases the optimality gap within the $1 \%$ range.

The quality of the stochastic solution is also dependent on the sample size chosen. Although a growing sample size in many cases leads to better or more stable results, it also limits the size of the instance which can be solved. However, the optimal sample size cannot be estimated in general since it is dependent on the characteristics of the instance solved. The tables presented in this section use the sample size of 10 or 100 dependent on the size of the problems which are considered.

Table 6 shows the impact of $\alpha$ on the results and computational times. It consists of five different orders which are routed separately on a network with 20 nodes and 100 services and the sample size considered for stochastic travel times is 100 . As the results show, if $\alpha$ is relatively low, then the stochastic results tend to be equal to the deterministic results. However, there still 
Table 7

The influence of the number of service on the computational times and the solution quality $(\alpha=0.95)$.

\begin{tabular}{|c|c|c|c|c|c|c|c|c|c|}
\hline \multirow[t]{2}{*}{ Instance } & \multirow[t]{2}{*}{ Sample size } & \multicolumn{2}{|c|}{ \# of Services (50) } & \multicolumn{2}{|c|}{ \# of Services (100) } & \multicolumn{2}{|c|}{ \# of Services (250) } & \multicolumn{2}{|c|}{ \# of Services (500) } \\
\hline & & $\begin{array}{l}\text { Objective } \\
\text { value }(€)\end{array}$ & $\begin{array}{l}\mathrm{CPU} \\
(\mathrm{s})\end{array}$ & $\begin{array}{l}\text { Objective } \\
\text { value }(€)\end{array}$ & $\begin{array}{l}\text { CPU } \\
(\mathrm{s})\end{array}$ & $\begin{array}{l}\text { Objective } \\
\text { value }(€)\end{array}$ & $\begin{array}{l}\text { CPU } \\
(\mathrm{s})\end{array}$ & $\begin{array}{l}\text { Objective } \\
\text { value }(€)\end{array}$ & $\begin{array}{l}\mathrm{CPU} \\
(\mathrm{s})\end{array}$ \\
\hline EU_20_1a & 1 & $1,774.02$ & 0.20 & $1,774.02$ & 0.60 & $1,774.02$ & 1.53 & $1,762.86$ & 2.66 \\
\hline EU_20_1a & 10 & $1,774.02$ & 0.79 & $1,774.02$ & 0.79 & $1,774.02$ & 3.64 & $1,762.86$ & 14.03 \\
\hline EU_20_1b & 1 & $1,990.01$ & 0.40 & $1,595.45$ & 0.54 & $1,595.45$ & 1.21 & $1,584.57$ & 2.09 \\
\hline EU_20_1b & 10 & $2,068.36$ & 0.46 & $1,595.45$ & 0.71 & $1,595.45$ & 3.17 & $1,584.57$ & 6.90 \\
\hline EU_20_1c & 1 & $3,563.68$ & 0.18 & $3,563.68$ & 0.53 & $3,563.68$ & 1.36 & $3,490.42$ & 2.14 \\
\hline EU_20_1c & 10 & Inf. & Inf. & $6,519.62$ & 1.12 & $3,645.95$ & 4.10 & $3,490.42$ & 16.60 \\
\hline EU_20_1d & 1 & $3,801.04$ & 0.21 & $3,354.09$ & 0.60 & $3,169.23$ & 1.32 & $3,158.07$ & 3.89 \\
\hline EU_20_1d & 10 & Inf. & Inf. & $4,531.2$ & 0.99 & $3,169.23$ & 3.47 & $3,158.07$ & 12.36 \\
\hline EU_20_1e & 1 & 762.49 & 0.18 & 746.57 & 0.50 & 447.57 & 1.09 & 447.57 & 3.83 \\
\hline EU_20_1e & 10 & 762.49 & 0.39 & 746.57 & 0.83 & 447.57 & 3.28 & 447.57 & 135.69 \\
\hline
\end{tabular}

Inf.: Infeasible solution

Table 8

Combined results for different number of services and orders for weights $(1,1,1)$ and $(1,0,0)$.

\begin{tabular}{|c|c|c|c|c|c|c|c|c|c|}
\hline \multirow[t]{3}{*}{ Instance } & \multirow[t]{3}{*}{$\alpha$} & \multicolumn{4}{|c|}{ Weight $=(1,1,1)$} & \multicolumn{4}{|c|}{ Weight $=(1,0,0)$} \\
\hline & & \multicolumn{2}{|c|}{ Deterministic } & \multicolumn{2}{|c|}{ Stochastic (sample size $=10$ ) } & \multicolumn{2}{|c|}{ Deterministic } & \multicolumn{2}{|c|}{ Stochastic (sample size $=10$ ) } \\
\hline & & $\begin{array}{l}\text { Objective } \\
\text { value }(€)\end{array}$ & $\begin{array}{l}\text { CPU } \\
(s)\end{array}$ & $\begin{array}{l}\text { Objective } \\
\text { value }(€)\end{array}$ & $\begin{array}{l}\text { CPU } \\
(\mathrm{s})\end{array}$ & $\begin{array}{l}\text { Objective } \\
\text { value }(€)\end{array}$ & $\begin{array}{l}\mathrm{CPU} \\
(\mathrm{s})\end{array}$ & $\begin{array}{l}\text { Objective } \\
\text { value }(€)\end{array}$ & $\begin{array}{l}\mathrm{CPU} \\
\text { (s) }\end{array}$ \\
\hline EU_20_1_50 & 0.95 & $1,774.02$ & 0.21 & $1,774.02$ & 0.43 & 1,740 & 0.26 & 1,740 & 0.76 \\
\hline EU_20_2_50 & 0.95 & $2,521.76$ & 0.38 & $2,521.76$ & 0.51 & 2,485 & 0.69 & 2,485 & 0.52 \\
\hline EU_20_5_50 & 0.95 & $8,076.24$ & 0.63 & $8,124.75$ & 0.82 & $7,775.5$ & 0.77 & $7,775.5$ & 0.93 \\
\hline EU_20_10_50 & 0.95 & $15,224.5$ & 4.50 & $15,363.4$ & 1.69 & $14,746.5$ & 0.82 & $14,866.5$ & 0.98 \\
\hline EU_20_20_50 & 0.95 & $31,980.2$ & 2.01 & $32,119.4$ & 2.18 & 31,072 & 1.41 & 31,192 & 1.75 \\
\hline EU_20_1_100 & 0.95 & $1,774.02$ & 0.35 & $1,774.02$ & 0.51 & 1,740 & 0.65 & 1,740 & 1.14 \\
\hline EU_20_2_100 & 0.95 & $2,521.76$ & 0.64 & $2,521.76$ & 1.53 & 2,485 & 0.72 & 2,485 & 1.09 \\
\hline EU_20_5_100 & 0.95 & $7,389.1$ & 1.59 & $7,389.1$ & 2.51 & $7,205.5$ & 1.63 & $7,205.5$ & 3.32 \\
\hline EU_20_10_100 & 0.95 & $14,014.3$ & 1.63 & $14,138.9$ & 25.20 & $13,651.5$ & 1.41 & $13,768.5$ & 27.93 \\
\hline EU_20_20_100 & 0.95 & $28,226.2$ & 74.69 & $28,350.8$ & 77.13 & 27,463 & 26.01 & 27,580 & 186.20 \\
\hline EU_20_1_250 & 0.95 & $1,774.02$ & 0.44 & $1,774.02$ & 1.23 & 1,740 & 0.73 & 1,740 & 2.05 \\
\hline EU_20_2_250 & 0.95 & $2,521.76$ & 1.14 & $2,521.76$ & 6.17 & 2,485 & 2.60 & 2,485 & 2.98 \\
\hline EU_20_5_250 & 0.95 & $7,389.1$ & 4.06 & $7,389.1$ & 10.63 & $7,205.5$ & 3.83 & $7,205.5$ & 11.64 \\
\hline EU_20_10_250 & 0.95 & $13,715.3$ & 35.06 & $\mathrm{X}$ & $\mathrm{X}$ & $13,337.5$ & 38.87 & $\mathrm{X}$ & $\mathrm{X}$ \\
\hline EU_20_20_250 & 0.95 & $\mathrm{X}$ & $\mathrm{X}$ & $\mathrm{X}$ & $\mathrm{X}$ & $\mathrm{X}$ & $\mathrm{X}$ & $\mathrm{X}$ & $\mathrm{X}$ \\
\hline EU_20_1_500 & 0.95 & $1,762.86$ & 1.82 & $1,762.86$ & 6.78 & 1,728 & 3.11 & 1,728 & 12.51 \\
\hline EU_20_2_500 & 0.95 & $2,510.6$ & 3.01 & $\mathrm{X}$ & $\mathrm{X}$ & 2,473 & 7.52 & $\mathrm{X}$ & $\mathrm{X}$ \\
\hline EU_20_5_500 & 0.95 & $7,348.99$ & 19.74 & $\mathrm{X}$ & $\mathrm{X}$ & $\mathrm{X}$ & $\mathrm{X}$ & $\mathrm{X}$ & $\mathrm{X}$ \\
\hline EU_20_10_500 & 0.95 & $x$ & $\mathrm{X}$ & $\mathrm{X}$ & $\mathrm{X}$ & $\mathrm{X}$ & $\mathrm{X}$ & $\mathrm{x}$ & $\mathrm{X}$ \\
\hline EU_20_20_500 & 0.95 & $\mathrm{X}$ & $\mathrm{X}$ & $\mathrm{X}$ & $\mathrm{X}$ & $\mathrm{X}$ & $\mathrm{X}$ & $\mathrm{X}$ & $\mathrm{X}$ \\
\hline
\end{tabular}

$\mathrm{X}$ : Not solved to optimality due to the time limit (10 minutes) or memory problem

might be a high probability of a delay or disruption on the chosen route. With the growing $\alpha$ the results are changing for orders $1 \mathrm{c}$ and $1 \mathrm{~d}$ which indicates that the deterministic routes might not be robust enough. Although the objective function values are much higher in these cases, the new route offers higher probability that the goods will arrive on time. The last column with $\alpha=1$ shows the results for the worst-case scenario in which the solution is feasible in $100 \%$ of the cases. The computational times are relatively equal for the lower values of $\alpha$ and they start to decrease with $\alpha=0.95$ and are very low for the worst-case scenario. This fact can be explained by the decreasing number of alternatives which are still feasible when $\alpha$ is growing.

The number of services is another limiting factor which influences not only the computational time but also the quality of the solution. As displayed in Table 7, the computational times for the deterministic solutions are increasing only slowly whereas the increase for stochastic solutions is much faster. Nevertheless, it is still possible to obtain an optimal solution for 500 services within less than 3 minutes. The sample size chosen for stochastic solution is 10 since this is the biggest sample size which allows to solve instances with 500 services. The impact on the solution can be seen especially for orders $1 \mathrm{c}$ and $1 \mathrm{~d}$ where there is no feasible solution for the stochastic version of the model in case of 50 services because the uncertainty in case of the deterministic route, which is the only possible connection in this small network, is very high and thus not acceptable for $\alpha=0.95$. With the increasing number of services also stochastic solutions are found for both orders and in general the costs of the optimal solution are decreasing. This is also due to the fact that the bigger instances contain a higher number of direct truck services and more combinations are possible in comparison to smaller instances with a limited number of services consisting mainly of trains and ships.

Tables 8 and 9 combine the number of services (between 50 and 500) and the number of orders (between 1 and 20) and show the results for different weight combinations. 
Table 9

Combined results for different number of services and orders for weights $(0,1,0)$ and $(0,0,1)$.

\begin{tabular}{|c|c|c|c|c|c|c|c|c|c|}
\hline \multirow[t]{3}{*}{ Instance } & \multirow[b]{3}{*}{$\alpha$} & \multicolumn{4}{|c|}{ Weight $=(0,1,0)$} & \multicolumn{4}{|c|}{ Weight $=(0,0,1)$} \\
\hline & & \multicolumn{2}{|c|}{ Deterministic } & \multicolumn{2}{|c|}{ Stochastic $($ sample size $=10)$} & \multicolumn{2}{|c|}{ Deterministic } & \multicolumn{2}{|c|}{ Stochastic $($ sample size $=10)$} \\
\hline & & $\begin{array}{l}\text { Objective } \\
\text { value ( } € \text { ) }\end{array}$ & $\begin{array}{l}\text { CPU } \\
(s)\end{array}$ & $\begin{array}{l}\text { Objective } \\
\text { value }(€)\end{array}$ & $\begin{array}{l}\text { CPU } \\
(\mathrm{s})\end{array}$ & $\begin{array}{l}\text { Objective } \\
\text { value }(€)\end{array}$ & $\begin{array}{l}\text { CPU } \\
(s)\end{array}$ & $\begin{array}{l}\text { Objective } \\
\text { value }(€)\end{array}$ & $\begin{array}{l}\text { CPU } \\
(\mathrm{s})\end{array}$ \\
\hline EU_20_1_50 & 0.95 & 0 & 0.46 & 0 & 0.56 & 34.02 & 0.25 & 34.02 & 0.81 \\
\hline EU_20_2_50 & 0.95 & 0 & 0.61 & 0 & 0.70 & 36.77 & 0.63 & 36.76 & 0.67 \\
\hline EU_20_5_50 & 0.95 & 0 & 0.67 & 48.504 & 1.05 & 199.27 & 0.51 & 270.38 & 0.92 \\
\hline EU_20_10_50 & 0.95 & 0 & 0.82 & 60.504 & 1.67 & 331.06 & 1.10 & 402.17 & 1.59 \\
\hline EU_20_20_50 & 0.95 & 0 & 0.85 & 60.504 & 2.28 & 684.95 & 1.21 & 756.05 & 1.76 \\
\hline EU_20_1_100 & 0.95 & 0 & 0.34 & 0 & 0.78 & 34.02 & 0.62 & 34.02 & 1.12 \\
\hline EU_20_2_100 & 0.95 & 0 & 0.46 & 0 & 1.20 & 36.76 & 0.72 & 36.76 & 1.26 \\
\hline EU_20_5_100 & 0.95 & 0 & 0.82 & 0 & 2.28 & 183.52 & 1.44 & 183.60 & 1.802 \\
\hline EU_20_10_100 & 0.95 & 0 & 1.24 & 0 & 89.66 & 315.03 & 1.41 & 315.11 & 13.08 \\
\hline EU_20_20_100 & 0.95 & 0 & 4.97 & 0 & 151.47 & 642.92 & 29.84 & 643.0 & 34.29 \\
\hline EU_20_1_250 & 0.95 & 0 & 0.93 & 0 & 1.39 & 33.6 & 0.76 & 33.6 & 1.24 \\
\hline EU_20_2_250 & 0.95 & 0 & 1.58 & 0 & 8.10 & 36.34 & 1.58 & 36.34 & 2.73 \\
\hline EU_20_5_250 & 0.95 & 0 & 3.91 & 0 & 43.59 & 182.40 & 3.44 & 182.48 & 33.56 \\
\hline EU_20_10_250 & 0.95 & 0 & 26.91 & $\mathrm{X}$ & $\mathrm{X}$ & 312.16 & 32.50 & $\mathrm{X}$ & $X$ \\
\hline EU_20_20_250 & 0.95 & 0 & 137.58 & $\mathrm{X}$ & $\mathrm{X}$ & 632.76 & 186.71 & $\mathrm{X}$ & $\mathrm{X}$ \\
\hline EU_20_1_500 & 0.95 & 0 & 1.59 & 0 & 8.66 & 30.66 & 1.99 & 30.66 & 12.86 \\
\hline EU_20_2_500 & 0.95 & 0 & 3.43 & $\mathrm{X}$ & $\mathrm{X}$ & 33.40 & 5.26 & $\mathrm{X}$ & $\mathrm{X}$ \\
\hline EU_20_5_500 & 0.95 & 0 & 19.41 & $\mathrm{X}$ & $\mathrm{X}$ & 178.41 & 26.10 & $\mathrm{X}$ & $\mathrm{X}$ \\
\hline EU_20_10_500 & 0.95 & $\mathrm{X}$ & $\mathrm{X}$ & $\mathrm{X}$ & $\mathrm{X}$ & $\mathrm{X}$ & $\mathrm{X}$ & $\mathrm{X}$ & $X$ \\
\hline EU_20_20_500 & 0.95 & $\mathrm{X}$ & $X$ & $X$ & $X$ & $X$ & $X$ & $X$ & $X$ \\
\hline
\end{tabular}

$\mathrm{X}$ : Not solved to optimality due to time limit (10 min) or memory problem

Table 10

The inclusion of demand uncertainty together with travel time uncertainty (sample size $=10$ ).

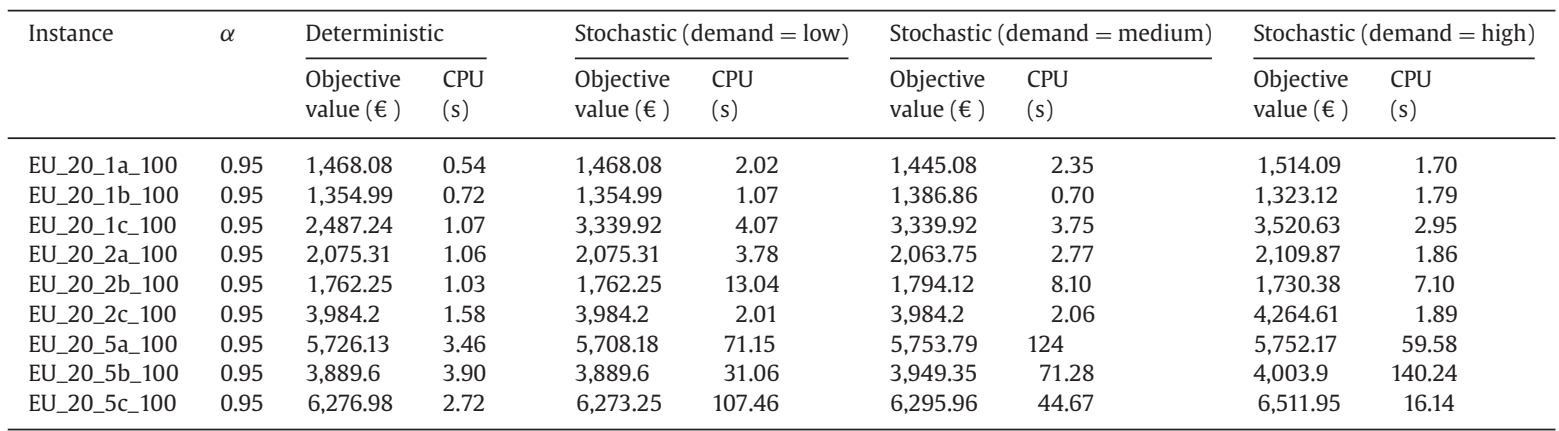

In all cases instances up to 20 nodes, 500 services and 5 orders are solvable deterministically with the exception of the instance $E U \_20 \_20 \_250$ for weights $(1,1,1)$ and $(1,0,0)$. For the stochastic version with the sample size of 10 the instance $E U \_20 \_5 \_250$ seems to be the limit. The limitation in this case is not the computational time but rather the memory since the size of the problems becomes easily too large for CPLEX to read it. The computational times are less than one minute for each of the considered instances with a maximum of slightly more than 3 minutes for one instance. The number of orders has a higher influence on the complexity of the problem than the number of services as it can be also seen from the computational times. The lowest computational times are achieved for the weights $(0,1,0)$ since in this case only the penalty costs for late arrival are considered and therefore the model just needs to find a solution where no delay occurs at the destination which was successfully found in all deterministic cases and in most of the stochastic cases. The benefits of additional services can be also seen in this case since the costs tend to decrease with the increasing number of services.

Next to the travel time uncertainty, demand uncertainty has been investigated as shown in Table 10. Demand uncertainty has been analyzed based on three different uncertainty levels, namely "low uncertainty", "medium uncertainty" and "high uncertainty". Thereby, medium uncertainty levels are based on our empirical analysis of traffic flow levels and thus match the probabilities used for the case study. Based on that, high uncertainty levels were chosen with twice as high probabilities for disrupted or congested states while in the low uncertainty case these probabilities were halved.

As seen from Table 10, demand uncertainty has impact on both the solution time and the quality. Depending on the uncertainty level, for some of the instances, the solution value increases with the increase in uncertainty level. More specifically, these instances (i.e., $E U \_20 \_1 c \_100, E U \_20 \_2 c \_100, E U \_20 \_5 c \_100$ ) are sensitive to the change in demand. Based on this analysis, it can be stated that demand uncertainty has impact but it is less affective than travel time uncertainty. 


\section{Conclusions and future research directions}

New trends, such as intermodal transportation, are extending existing transportation systems and integrating available transportation options in a sustainable way. The integration among transportation modes, such as road, rail and maritime transportation, potentially increases harmonization efforts for multiple transportation users. This could be achieved by considering not only monetary costs but also customer satisfaction (i.e., timely delivery), and environmental concerns of the transportation.

In this paper, we have proposed a novel continuous-time mixed-integer linear programming formulation which evaluates the time of occurrence of transportation activities and the number of containers transhipped on transportation services (i.e., truck, train and barge). The model extends the fixed charge network design formulation by considering the synchronization of the transportation services and supporting the multi-objective nature of the SND-oriented problems. Moreover, the proposed formulation considers the travel time uncertainty, which is one of the most crucial factors affecting the reliability of intermodal transportation. In order to deal with uncertainty in travel times, we have applied sample average approximation algorithm which evaluates an extensive set of scenarios in order to develop more robust transportation plans in terms of selected costs, time, or environmental objectives.

We have validated the proposed methodology on a real-life case study. Our results indicate that the proposed stochastic mathematical formulation generates robust solutions that compare favorably with solutions generated by a deterministic formulation. To fully evaluate the effectiveness of the proposed approach, we generated different sets of instances based on real geographic data and compiled a library of GISND-TTU instances. We have presented results of extensive computational experimentation using the proposed stochastic methodology and have compared it against the solutions produced using the deterministic formulation. The results show that the proposed algorithm is highly effective in finding good-quality and robust solutions on instances with up to 20 locations and 500 transportation services.

Considering the development of the intermodal transportation, the following two areas were identified as further research directions, which include: $(i)$ extending the formulation to generate the transportation plan with asset management consideration, and (ii) developing the dynamic programming algorithm to consider the real-time characteristics of data.

\section{Acknowledgments}

The authors gratefully acknowledge funding provided by the European Union's Seventh Framework Programme (FP7/20072013) under grant agreement 318275 (GET Service), by the Technology University of Eindhoven and by the WU Vienna University of Economics and Business. We thank the Editor in Chief Professor Hai Yang, the Guest Editor, and the two anonymous reviewers for their constructive comments, which helped us in improving the paper.

\section{References}

Agra, A., Christiansen, M., Figueiredo, R., Hvattum, L.M., Poss, M., Requejo, C., 2013. The robust vehicle routing problem with time windows. Computers \& Operations Research 40 (3), 856-866.

Ahn, K., Rakha, H., Trani, A., Van Aerde, M., 2002. Estimating vehicle fuel consumption and emissions based on instantaneous speed and acceleration levels. Journal of Transportation Engineering 128, 182-190.

Andersen, J., Crainic, T.G., Christiansen, M., 2009. Service network design with management and coordination of multiple fleets. European Journal of Operational Research 193, 377-389.

Bai, R., Wallace, S.W., Li, J., Chong, A.-L., 2014. Stochastic service network design with rerouting. Transportation Research Part B: Methodological 60, 50-65.

Barth, M., Boriboonsomsin, K., 2008. Real-world $\mathrm{CO}_{2}$ impacts of traffic congestion. Transportation Research Record 2058, 163-171.

Bauer, J., Bektas, T., Crainic, T., 2010. Minimizing greenhouse gas emissions in intermodal freight transport: an application to rail service design. Journal of the Operational Research 61, 530-542.

Bertsimas, D., Simchi-Levi, D., 1996. A new generation of vehicle routing research: Robust algorithms, addressing uncertainty. Operations Research 44 (2), 286304.

Boulter, P., McCrae, I., 2007. Assessment and Reliability of Transport Emission Models and Inventory Systems - Final Report. Technical Report. TRL.

Boulter, P., McCrae, I., 2009. ARTEMIS: assessment and reliability of transport emission models and inventory systems: final report. Technical Report. Berkshire, United Kingdom.

Bowyer, D., Akcelik, R., Biggs, D., 1985. Guide to Fuel Consumption Analysis for Urban Traffic Management. Technical Report. Australian Road Research Board Transport Research.

Chang, T.S., Wan, Y.W., Ooi, W.T., 2009. A stochastic dynamic traveling salesman problem with hard time windows. European Journal of Operational Research 198 (3), 748-759.

Crainic, T., Fu, X., Gendreau, M., Rei, W., Wallace, S.W., 2011. Progressive hedging-based metaheuristics for stochastic network design. Networks: An International Journal 58 (2), 114-124.

Crainic, T.G., 2000. Service network design in freight transportation. European Journal of Operational Research 122, $272-288$.

Crainic, T.G., 2003. Long-Haul freight transportation. In: Handbook of Transportation Science. In: 56, 56. Springer US, pp. 451-516.

Danese, P., Romano, P., Bortolotti, T., 2012. JIT production, JIT supply and performance: investigating the moderating effects. Industrial Management \& Data Systems 112 (3), 441-465.

Demir, E., Bektas, T., Laporte, G., 2011. A comparative analysis of several vehicle emission models for road freight transportation. Transportation Research Part D $16,347-357$.

Demir, E., Bektas, T., Laporte, G., 2014. A review of recent research on green road freight transportation. European Journal of Operational Research 237, 775-793.

Demir, E., Huang, Y., Scholts, S., Van Woensel, T., 2015. A selected review on the negative externalities of the freight transportation: modeling and pricing. Transportation Research Part E: Logistics and Transportation Review 77, 95-114.

DSLV, 2013. Berechnung von Treibhausgasemissionen in Spedition und Logistik gemäß DIN EN 16258. Technical Report. DSLV.

ECMT, 1993. European conference of ministers of transport: Terminology on combined transport.

Eichlseder, H., Hausberger, S., Rexeis, M., Zallinger, M., Luz, R., 2009. Emission Factors from the Model PHEM for the HBEFA Version 3. Technical Report. TU Graz Institute for Internal Combustion Engines and Thermodynamics.

Eksioglu, B., Vural, A.V., Reisman, A., 2009. The vehicle routing problem: a taxonomic review. Computers \& Industrial Engineering 57 (4), $1472-1483$. 
ESRL, 2015. NOAA In Situ Carbon Dioxide $\left(\mathrm{CO}_{2}\right)$ Measurements. Technical Report. National Oceanic and Atmospheric Administration. Available at: http://www. esrl.noaa.gov/gmd/obop/mlo/programs/esrl/co2/co2.html(1.7.2015)

EU, 2013. Energy, transport and environment indicators. Technical Report. Eurostat Pocketbooks, Luxemburg: European Commission.

European Commission, 2012. Measuring Road Congestion. Technical Report. European Commission.

European Commission, 2014. Road transport: reducing $\mathrm{CO}_{2}$ emissions from vehicles. Available at: http://ec.europa.eu/clima/policies/transport/vehicles/index_en. $\operatorname{htm}(1.7 .2015)$.

Eurostat, 2013. Freight transport statistics. Available at: http://epp.eurostat.ec.europa.eu/statistics_explained/index.php/Freight_transport_statistics (1.7.2015).

Forkenbrock, D., 1999. External costs of intercity truck freight transportation. Transportation Research Part A: Policy and Practice 33 (7-8), $505-526$.

Geerlings, H., van Duin, R., 2011. A new method for assessing $\mathrm{CO}_{2}$-emissions from container terminals: a promising approach applied in Rotterdam. Journal of Cleaner Production 19, 657-666.

Gendreau, M., Laporte, G., Séguin, R., 1996. Stochastic vehicle routing. European Journal of Operational Research 88 (1), 3-12.

Guener, A.R., Murat, A., Chinnam, R.B., 2012. Dynamic routing under recurrent and non-recurrent congestion using real-time its information. Computers \& Operations Research 39 (2), 358-373.

Hoff, A., Lium, A.-G., Løkketangen, A., Crainic, T.G., 2010. A metaheuristic for stochastic service network design. Journal of Heuristics 16 (5), $653-679$.

IBM ILOG, 2015. Copyright CInternational Business Machines Corporation 1987.

IFEU, 2011. Ecological Transport Information Tool for Worldwide Transports -Methodology and Data Update. Technical Report. UIC.

IFEU, 2012. Aktualisierung "Daten- und Rechenmodell: Energieverbrauch und Schadstoffemissionen des motorisierten Verkehrs in Deutschland 1960-2030" (TREMOD, Version 5.3) für die Emissionsberichtserstattung 2013 (Berichtsperiode 1990-2011). Technical Report. IFEU Heidelberg.

IPCC, 2007. Climate change 2007. Synthesis Report. Technical Report. Intergovernmental Panel on Climate Change, publisher Geneva, Switzerland. Available at: https://www.ipcc.ch/pdf/assessment-report/ar4/syr/ar4_syr.pdf (1.7.2015).

Jaillet, P., 1988. A priori solution of a traveling salesman problem in which a random subset of the customers are visited. Operations Research 36 (6), $929-936$.

Jennings, B., Holcomb, M., 1996. Beyond containerization: the broader concept of intermodalism. Transportation Journal 35 (3), 5-13.

Kenyon, A.S., Morton, D.P., 2003. Stochastic vehicle routing with random travel times. Transportation Science 37 (1), $69-82$.

Kombiverkehr, 2014. Fahrplanauskunft. Available at: http://www.kombiverkehr.de/web/Deutsch/Startseite/ (1.7.2015).

Kotabe, M., Murray, J.Y., 2004. Global sourcing strategy and sustainable competitive advantage. International Marketing Management 33, 7-14.

Kranke, A., Schmied, M., Schön, A.D., 2011. $\mathrm{CO}_{2}$-Berechnung in der Logistik. Munich: Verlag Heinrich Vogel.

Kummer, S., 2006. Einführung in die Verkehrswirtschaft. Vienna: Facultas.

Laporte, G., Louveaux, F.V., Mercure, H., 1994. A priori optimization of the probabilistic traveling salesman problem. Operations Research 42 (3), 543-549.

Lium, A.-G., Crainic, T.G., Wallace, S.W., 2009. A study of demand stochasticity in service network design. Transportation Science 43 (2), $144-157$.

Luedtke, J., Ahmed, S., 2008. A sample approximation approach for optimization with probabilistic constraints. SIAM Journal on Optimization 19 (2), 674-699.

Metrans, 2014. Intermodal services - train schedule - july 2014. Available at: http://www.metrans.eu/intermodal-services/train-schedule-1/ (1.7.2015).

NTM, 2008. Calculation Methods and Default Data - Mode-Specific Issues - Sea Transport. Technical Report. Network for Transport and Environment, Sweden.

OECD, 2010. Globalisation, transport and environment. Available at: http://www.oecd.org/greengrowth/greening-transport/45095528.pdf (1.7.2015).

Pagnoncelli, B., Ahmed, S., Shapiro, A., 2009. Sample average approximation method for chance constrained programming: theory and applications. Journal of Optimization Theory and Applications 142 (2), 399-416.

PLANCO, 2007. Verkehrswirtschaftlicher und ökologischer Vergleich der Verkehrsträger Straße, Schiene und Wasserstraße. Technical Report. PLANCO.

PTV, 2014. Ptv Map \& Guide. Available at: http://www.mapandguide.com/de/home/ (1.7.2015).

SteadieSeifi, M., Dellaert, N., Nuijten, W., Van Woensel, T., Raoufi, R., 2014. Multimodal freight transportation planning: a literature review. European Journal of Operational Research 233, 1-15.

UIC, 2012. 2012 Report on Combined Transport in Europe. Technical Report. UIC.

UNCTAD, 2013. Review of Maritime Transport. United Nations. Available at: http://unctad.org/en/publicationslibrary/rmt2013_en.pdf (1.7.2015).

Vannieuwenhuyse, B., Gelders, L., Pintelon, L., 2003. An online decision support system for transportation mode choice. Logistics Information Management 16, $125-133$.

Verweij, B., Ahmed, S., Kleywegt, A.J., Nemhauser, G., Shapiro, A., 2003. The sample average approximation method applied to stochastic routing problems: a computational study. Computational Optimization and Applications 24 (2--3), 289-333.

via donau, 2006. COLD - Container Liniendienst Donau - Eine Einschätzung der Chancen und Risiken von Containertransporten auf der Donau zwischen Österreich und dem Schwarzen Meer. Technical Report. via donau. Available at: http://www.via-donau.org/fileadmin/group_upload/5/projektseiten/cold/ COLD_Endbericht__Anhang.pdf (1.7.2015).

via donau, 2007. Manual on Danube Navigation. Vienna: via donau.

Wang, S., Meng, Q., 2012. Robust schedule design for liner shipping services. Transportation Research Part E: Logistics and Transportation Review 48 (6), $1093-$ 1106.

Wang, T., Meng, Q., Wang, S., Tan, Z., 2013. Risk management in liner ship fleet deployment: a joint chance constrained programming model. Transportation Research Part E: Logistics and Transportation Review 60, 1-12.

Wieberneit, N., 2008. Service network design for freight transportation: a review. OR Spectrum 30, 77-112. 